\title{
Women's entrepreneurship and intimate partner violence: A cluster randomized trial of microenterprise assistance and partner participation in post-conflict Uganda (SSM-D-14-01580R1) ${ }^{\text {th }}$
}

\author{
Eric P. Green ${ }^{\mathrm{a}, *}$, Christopher Blattman ${ }^{\mathrm{b}}$, Julian Jamison ${ }^{\mathrm{c}}$, Jeannie Annan ${ }^{\mathrm{d}}$ \\ ${ }^{a}$ Duke Global Health Institute, Box 90519, Durham, North Carolina 27708, USA \\ ${ }^{b}$ Columbia University SIPA, 420 W 118th St, New York, NY 10027, USA \\ ${ }^{c}$ Consumer Financial Protection Bureau, 1700 G St NW, Washington, DC 20552, USA \\ ${ }^{d}$ International Rescue Committee, 122 East 42nd Street, New York, NY 10168, USA
}

\footnotetext{
* A Vanguard Charitable Trust and the LOGiCA Trust Fund at the World Bank funded data collection and analysis. This article is the result of independent research and does not necessarily represent the views of the Consumer Financial Protection Bureau or the United States. For research assistance, we thank Filder Aryemo, Natalie Carlson, Lindsay Dolan, Mathilde Emeriau, Christian Lehmann, Sara Lowes, Lucy Martin, Godfrey Okot, Richard Peck, Alexander Segura, Xing Xia, and Adam Xu through Innovations for Poverty Action (IPA).

*Please address correspondence to Eric Green, 1(919)666-7111

Email addresses: eric.green@duke.edu (Eric P. Green), chrisblattman@columbia.edu (Christopher Blattman), julison@gmail.com (Julian Jamison), jeannie.annan@rescue.org (Jeannie Annan)
} 


\begin{abstract}
Intimate partner violence is widespread and represents an obstacle to human freedom and a significant public health concern. Poverty alleviation programs and efforts to economically "empower" women have become popular policy options, but theory and empirical evidence are mixed on the relationship between women's empowerment and the experience of violence. We study the effects of a successful poverty alleviation program on women's empowerment and intimate partner relations and violence from 2009 to 2011. In the first experiment, a cluster-randomized superiority trial, 15 marginalized people ( $86 \%$ women) were identified in each of 120 villages $(n=1,800)$ in Gulu and Kitgum districts in Uganda. Half of villages were randomly assigned via public lottery to immediate treatment: five days of business training, $\$ 150$, and supervision and advising. We examine intent-to-treat estimates of program impact and heterogeneity in treatment effects by initial quality of partner relations. 16 months after the initial grants, the program doubled business ownership and incomes $(\mathrm{p}<0.01)$; we show that the effect on monthly income, however, is moderated by initial quality of intimate partner relations. We also find small increases in marital control $(\mathrm{p}<0.05)$, self-reported autonomy $(\mathrm{p}<0.10)$, and quality of partner relations $(\mathrm{p}<0.01)$, but essentially no change in intimate partner violence. In a second experiment, we study the impact of a low-cost attempt to include household partners (often husbands) in the process. Women from the 60 waitlist villages $(n=904)$ were randomly assigned to participate in the program as individuals or with a household partner. We observe small, non-significant decreases in abuse and marital control and large increases in the quality of relationships $(\mathrm{p}<0.05)$, but no effects on women's attitudes toward gender norms and a non-significant reduction in autonomy. Involving men and changing framing to promote more inclusive programming can improve relationships, but may not change gender attitudes or increase business success. Increasing women's earnings has no effect on intimate partner violence.
\end{abstract}

Keywords: Uganda, poverty, gender, cash transfers, microenterprise, empowerment,

intimate partner violence, post-conflict 
Enterprise, Empowerment and IPV

\section{Introduction}

2 Intimate partner violence (IPV) - abusive or controlling behaviors toward intimate partners (Dixon \& Graham-Kevan, 2011) - is the most common type of

4 violence against women (Garcia-Moreno \& Watts, 2011). A 10-country study showed 15 to 71 percent of women experience IPV over their lifetimes (Garcia-

6 Moreno et al., 2006). In conflict settings, reports of IPV exceed those of rape and sexual violence from men outside the home (Stark \& Ager, 2011). Some 8 estimates of the economic cost of IPV suggest it is greater than that of civil war or homicides globally (Fearon \& Hoeffler, 2014).

This paper investigates how a widely used economic intervention might also prevent IPV. Reducing IPV is an end it itself, since women's agency and 12 empowerment, including freedom from coercion, is central to the pursuit of development as human freedom (Sen, 1999). IPV is also a public health con-

14 cern because of its association with poor physical and mental health, including depressive symptoms and suicide (Devries et al., 2011; Beydoun et al., 2012) 16 and HIV infection (Jewkes et al., 2010).

One common approach is to address IPV directly through education or

18 
24

26 involve male household members, typically partners.

\section{${ }_{42}$ Economic Empowerment, Poverty and IPV}

The theoretical literature has ambiguous predictions about the effects of in44 creasing women's income and work outside the home on IPV (for reviews see Aizer, 2010; Hidrobo \& Fernald, 2013). Some predict that increasing women's 
income shares decreases violence. For instance, some sociologists and feminists see financial inequality between the sexes and women's economic dependency as root causes of IPV. Similarly, economic models of household bargaining commonly suggest that as a woman's options outside of the marriage improve, her tolerance for violence decreases, and the husband will strategically use less of it, lest he lose his wife and her income.

Others predict an increase in violence. Some sociologists argue that increases in women's incomes increase tensions between partners, provoke emo54 tional backlashes, or lead men to use violence to reinstate authority. Some economists have also argued that, when a woman values a marriage intrinsically or where divorce is not a credible threat, men may use violence to capture the woman's resources. Thus violence can increase with income or transfers to women.

Research on violence against women shows multiple risk factors across the social ecology and suggests that interventions must address multiple risk factors at individual, family, and systemic levels over a significant period of 62 time in order to sustain change (Ellsberg et al., 2014; Jewkes et al., 2014). The empirical evidence about how best to increase women's empowerment is 64 still thin and mixed (Vyas \& Watts, 2009; Ellsberg et al., 2014), however, including whether economic interventions improve empowerment on their own 66 or whether supplemental interventions to address inequalities are needed.

The first experimental evidence regarding economic empowerment and 68 IPV comes from a cluster-randomized trial of a group-based microfinance and 
gender and HIV training program for poor, rural women in South Africa

70 (Pronyk et al., 2006; Kim et al., 2009). A per protocol analysis suggests that the combined program reduced IPV by more than half and improved partner 72 relations; a secondary analysis shows that microfinance alone has little effect on norms or IPV (Kim et al., 2009). More recent studies of cash transfer pro74 grams in Mexico and Peru offer mixed results (Angelucci, 2008; Bobonis et al., 2013; Hidrobo \& Fernald, 2013). Unconditional cash transfers in Kenya and 76 Ecuador show significant reductions in IPV (Haushofer \& Shapiro, 2013).

\section{Engaging Men}

78 and normative behavior, such as gender-based violence, by watching others

The rationale for addressing IPV through men's discussion groups is based on the belief that socially constructed gender norms about inequality are a root cause of violence (Barker et al., 2010). Girls and boys learn gender roles and observing rewards and punishments; this is the basis of social learning theory (Bandura, 1973), one of several theoretical etiologies of IPV (for a review see Dixon \& Graham-Kevan, 2011). Understanding and addressing the connection between violence and masculinity is also critical, gender theorists argue (Jewkes et al., 2014). 'Gender-transformative' programs are therefore designed to change gender norms and to promote gender equality among men and boys, most often by raising awareness and targeting attitudes throughout the social ecology.

Few interventions engaging men directly to reduce violence have been rig- 
orously assessed (Ellsberg et al., 2014; Jewkes et al., 2014), especially outside 92 of high-income countries. One of the first studies of the men's discussion group approach was a cluster-randomized trial in South Africa of Stepping Stones, 94 an eight-week participatory learning program on sexual health for both genders. Men reported reductions in physical and sexual violence perpetration 24 96 months afterwards, but women did not report less victimization Jewkes et al. (2008). More recently in post-conflict Cote D'Ivoire, a randomized evaluation ${ }_{98}$ of an IPV prevention program consisting of men's discussion groups showed small but non-significant reductions in women's reports of physical and/or 100 sexual IPV (Hossain et al., 2014).

The economic program we evaluate, however, targets women, not men. 102 As we will describe, our program experience and previous qualitative work suggest that it is important to engage men in the process, but there was not much evidence at the time to inform the program design. Interventions that have worked with men and women partners simultaneously have largely been the domain of psychotherapy. In high-income countries, couples therapy is a well-established strategy for improving relationship quality and reducing 108 conflict (i.e. disputes) between partners (Snyder \& Halford, 2012), the latter being a strong correlate of physical violence against women (Jewkes, 2002). 110 This is not the case in most low-income countries where psychotherapy is unavailable to the poor. Since our study commenced, a randomized trial of 112 a group savings program in Cote D'Ivoire that added a couples discussions group $(E A \$ E)$ addressing household economic issues while implicitly touching 114 gender norms found a significant reduction of physical violence in the per 
protocol analysis for women who attended more than 75 percent of sessions 116 (Gupta et al., 2013).

\section{Current Study}

In 2009, an Italian non-governmental agency, the Association of Volunteers in International Service (AVSI), designed a cash transfer program called PROGRAM NAME OMITTED to help ultrapoor women with little formal education to develop small businesses. AVSI aimed to increase women's incomes and autonomy. Asset transfer programs are one of the most commonplace aid programs for the extreme poor. In addition to providing cash, livestock, or some other capital, such programs typically offer a bundle of services, including training, formation of self-help groups, and supervision. AVSI's program is unusual in that it offered cash instead of livestock and encouraged ultrapoor women to start nonfarm businesses like petty trading. This is an important model to explore, if only because cash is much cheaper to deliver than livestock.

As reported in Blattman et al. (2014), this microenterprise program led to large, experimentally identified increases in employment and earningsimpacts that were at least as cost-effective as livestock-based programs. We hypothesized, however, that these average impacts concealed substantial variation. In particular, our qualitative work led us to hypothesize that poor intimate partner relationships are an obstacle to developing successful small-scale businesses. And according to Saile et al. (2013), dysfunctional intimate partner relationships are common in this setting. In a study of nine conflict-affected 
communities in 2010, more than 70 percent of women reported experiencing

138

at least one type of verbal, psychological, or physical abuse in the past year. These observations motivated a follow-up experiment that is the focus of the current paper.

In a second phase of implementation, clients either received the standard program of business skills training and support described above or a variant called Women Plus $(\mathrm{W}+)$. In the standard program, now called Tii ki komi in Luo or "Work by/for yourself improvement", clients participated as individuals. In the $\mathrm{W}+$ variant, program clients were encouraged to participate in the training and follow-up visits with someone from their household who helps to make financial decisions. For most women, this meant participating with an intimate male partner/spouse or another important male figure, such as a father or brother. In both variants, the money went to the women. For $\mathrm{W}+$ participants, however, the framing of the support shifted from a grant wholly controlled by the woman to a grant encouraging household input into decisionmaking. The new framing is captured in the $\mathrm{W}+$ program name presented to clients: Tic kacel ryemo can or "Let's work together to reduce poverty".

Thus in addition to testing the effects of the standard program on women's autonomy and IPV, this study tests whether a low-cost variation-a slight reframing, basic training in couples' communication and problem solving, and joint participation in the program - augments economic success while achieving the empowerment outcomes that were elusive in the first implementation.

Based on our review of the literature and the results of our initial study, 
we theorized that this more inclusive approach would lead to a measurable impact in the partner's direct and indirect support for the business - from relaxing constraints placed on the woman, to providing emotional support that helps the woman to juggle all of her responsibilities, to actively participating in business operations. We further hypothesized that partner relations would be improved through reductions in tensions and IPV, resulting from the household's increased economic security and the couple's ability to communicate and work together. We also hypothesized that experimentation with new gendered behavior patterns combined with business success and improvements in relationship quality would begin to change men's and women's attitudes about gender roles.

\section{Methods}

\section{Setting and Context}

This study was conducted in northern Uganda between 2009 and 2011, fol174 lowing two decades of civil war between the Government of Uganda and the Lord's Resistance Army. Security improved in 2005 as the rebel group fled 176 the country. When the study began in 2009, most of the 2 million people displaced because of the war had returned home from nearby displacement camps. Although people exhibited psychological resilience, war and displacement left most impoverished and without the human and financial capital to pursue non-agricultural income-generating activities (Annan et al., 2006). 
Enterprise, Empowerment and IPV

\section{Intervention}

The PROGRAM NAME OMITTED (PROGRAM) program included four days of business skills training, a start-up grant of approximately $\$ 150$ USD, and follow-up support by trained field staff. The training taught participants"clients" - how to create a business plan, budget, market goods and services, and keep basic financial records. At the end of the training, clients prepared written business plans (with help from AVSI staff if illiterate). AVSI staff disbursed cash in two installments and visited the clients approximately every six weeks for six months to monitor spending and provide advice.

In rural Uganda, like much of sub-Saharan Africa, men and women engage in a mix of crop sales, animal raising, casual labor, and small non-farm self-employment, such as petty trading. Women commonly engage in all these activities. But animal-raising and non-farm businesses usually require some starting capital, and the women in our sample were generally too poor to start them and had no source of credit. AVSI's program was designed to overcome these constraints.

In a variant of the program called Women Plus $(\mathrm{W}+)$, clients were invited to participate with household partners, thus changing the framing. The $\mathrm{W}+$ program also added one day to the training to cover additional material on (i) cultural, gender, and financial barriers to female entrepreneurship), (ii) communication (a common component of couples therapy), and (iii) joint-problem solving (see Online Appendix A; [INSERT LINK TO ONLINE FILE]). 
Enterprise, Empowerment and IPV

\section{Research Design}

domized to Phase 1 and $n=904$ in villages randomized to delayed treatment).

214 Figure 1 displays a CONSORT-style participant flow diagram.

[Figure 1 about here.]

When it was time for the 60 delayed treatment villages to participate in the program (Phase 2), they were randomized to receive the standard program ${ }_{218}$ (no group dynamics; $\left.n=439\right)$ or the $\mathrm{W}+$ variant described above $(n=465)$. In each delayed treatment village, individual clients were also randomized to for a discussion of the cross-cutting designs and results). The Uganda National 222 University and Columbia University approved the research protocol. 
Enterprise, Empowerment and IPV

224

In early 2009, AVSI held public meetings to introduce the program and asked each community to nominate 20 of the most vulnerable people to take part. AVSI stipulated that three-fourths should be women aged 14 to 30 . AVSI screened 2,300 nominees and selected 1,800 (10 to 17 per village) to participate, screening out the least poor based on the results of interviews and home visits. Thus there was no self-selection into the study.

The author-led research team conducted baseline surveys with all enrolled participants between April and June 2009. Because illiteracy rates are high, Ugandan enumerators (who were not involved in program delivery) administered surveys verbally and captured responses using handheld computers. They conducted surveys in private settings and obtained informed consent. The author team trained enumerators on how to administer sensitive questions about IPV and other private issues.

Villages were randomly assigned to immediate treatment or delayed treatment via a public lottery held in each district. Roughly 20 months later-16 months after clients in the immediate treatment group received their cash grants - all participants were surveyed again. Survey enumerators were not blinded to treatment assignment due to the nature of some survey questions.

Following this survey, the 60 villages in the delayed treatment group were randomly assigned via computer algorithm to participate in the standard version of PROGRAM or the $\mathrm{W}+$ variant (1:1 allocation). Individual clients within each village (904 total) were also randomly assigned to follow-up. This 
cohort of clients was surveyed a final time between June and August 2012,

\section{Primary Outcome Measures \\ Primary Outcome Measures} approximately one year after receiving cash grants.

sso Our primary individual-level outcomes included IPV, attitudes toward gender norms, quality of relationship with partner, support from partner, and autonomy and influence in household purchases (see Table 1). Measures were created by the research team or adapted from a subset of the 2006 Uganda DHS (Uganda Bureau of Statistics (UBOS) \& Macro International Inc, 2007). To measure attitudes toward gender norms, we asked clients to rate their agreement with several statements about women's rights and justifications for wife beating. We created a composite partner relationship score by standardizing clients' responses to seven questions about relationship quality, communication patterns, listening skills, and dispute frequency. We constructed two composite scores for partner support of household (e.g., help with chores) and business activities, and we combined these scores into an overall partner support composite. Lastly, we constructed a composite autonomy/influence score from three questions representing a client's autonomy and influence in purchases (can decide how to spend money, can use earnings to buy clothes without permission, has a say in purchase of large household assets). Additional details about the measurement of each outcome are provided in the Online Appendix B [INSERT LINK TO ONLINE FILE]. Items in tables and figures marked with the $\dagger$ symbol refer to "partner who helps [client] make 
domestic and financial decisions" and may not refer specifically to the client's

intimate partner.

[Table 1 about here.]

272 about three alternative measures of income (cash earnings, non-durable con274 regression:

$$
Y_{i j}=\theta T_{j}+X_{i j} \beta+\varepsilon_{i j}
$$

282 random assignment to treatment (e.g. assignment to immediate or delayed 284 is a vector of controls including a district fixed effect, road distances between 
villages, and 90 baseline (i.e., before Phase 1) and midline (i.e., after Phase 1 but before Phase 2) covariates (see Table C.1 in the Online Appendix). We include distance measures to account for and estimate potential spillovers from clients in treatment villages to those in wait-list villages (see Blattman et al. (2014) for more details about spillover effects in Phase 1). Robust standard errors are clustered by village.

AVSI and the authors designed the $\mathrm{W}+$ intervention principally for women with partners. As a consequence, for Phase 2 analyses, we focus on ITT results among two subsets of our sample: 1) all women and 2) women who reported having intimate male partners during the survey that took place immediately before the Phase 2 program was implemented. The study was powered $(80 \%)$ to detect a 0.27 standard deviation (or larger) increase in 298 quality of partner relations given 60 clusters of 15 participants each with a $k$ of 0.03 . those who brought partners when assigned to $\mathrm{W}+$. Assignment to $\mathrm{W}+$ is unlikely to affect outcomes through other channels. If so, we can also calculate a treatment-on-the-treated (TOT) estimate of the average treatment effect, which uses random assignment to treatment as an instrument for the effect of actually bringing someone else (not necessarily an intimate male partner) to the training on outcomes (Angrist \& Pischke, 2008). This treatment effect can be interpreted as the impact of the program on compliers. To facilitate comparison to previous empirical work on IPV and economic assistance pro- 
grams (Pronyk et al., 2006; Gupta et al., 2013), we also report the results of

310 a per protocol (PP) analysis conducted among the subsample of women with intimate male partners. Women assigned to $\mathrm{W}+$ were included in the analysis 312 if they attended at least two days of training with an intimate male partner specifically.

\section{${ }_{314}$ Results}

\section{Study Sites and Participants}

Table 2 reports baseline characteristics of study sites and participants. The average village population is 699 , and most range from 350 to 1,000 people. The average village is 45 kilometers from the district capital.

[Table 2 about here.]

(1)

The average client in the sample was 27.3 years old and completed 2.8 years of education. 85.9 percent of the sample was female, and 47.9 percent were married and living with a partner. On average, clients reported working 15.4 hours week in the past month, principally farming. On average, reported cash earnings in the previous month were 8,938 UGX, roughly $\$ 4.47$ USD. Table C.2 in the Online Appendix [INSERT LINK TO ONLINE FILE] compares clients assigned to delayed treatment (thus the sample for the randomization to $\mathrm{W}+$ in Phase 2) to villagers not enrolled in the program. All villagers were poor, but clients reported slightly less education, employment and income. 
Enterprise, Empowerment and IPV

\section{Randomization Balance}

330 There was moderate imbalance in Phase 1 baseline covariates between individuals assigned to immediate treatment (Phase 1) or delayed treatment (Phase

332 2), but little imbalance in the Phase 2 assignment to the standard program or $\mathrm{W}+$. See Table 2 for the results of an OLS regression of baseline covariates 334 on indicators of assignment to treatment (Phase 1 versus Phase 2; standard program versus $\mathrm{W}+$ in Phase 2). The results suggest that the immediate treat-

\section{Treatment Compliance}

342 All 120 villages randomized to immediate or delayed treatment participated in the program in the allocated order, and no clusters were lost. At the individual level, there were no crossovers from wait-list control to immediate treatment in Phase 1 or from the standard program (control) to $\mathrm{W}+$ (treatment) in Phase 2. Of the original 896 clients randomized to immediate treatment, 860 participated in the program in Phase 1 (96.0\%). Reasons for non-participation included movement out of the subcounty, health issues, and other personal concerns. 

domized to the standard PROGRAM $(n=439)$ or $\mathrm{W}+(n=465)$ prior to the 352

As shown in Figure 1, 904 clients in the wait-list control group were ranstart of Phase 2. Clients assigned to $\mathrm{W}+$ were encouraged to participate in the program with someone in the household who helped to make important decisions, and $87.0 \%$ of women complied. Compliance for $\mathrm{W}+$ is defined as receiving the grant, attending the training sessions, and having a partner (not necessarily an intimate partner) who attended at least 2 days of the training. The program had 100 percent attendance among the grant recipients, so noncompliance in $\mathrm{W}+$ is related to partners' attendance.

\section{Survey Attrition}

survey attrition (loss-to-follow-up) was minimal in both phases. We completed surveys with all clients at the Phase 1 baseline and found 96 percent of clientsincluding migrants - for the survey conducted at the end of Phase 1. We also found 96 percent of the Phase 2 sample at the conclusion of Phase 2. Tables C.3 and C.4 in the Online Appendix [INSERT LINK TO ONLINE FILE] report complete survey response rates and demonstrate that attrition 66 is not generally significantly correlated with treatment or baseline covariates. Unfound participants were slightly younger and less educated, but more likely to be attending school. 


\section{Phase 1 Treatment Effects}

Economic outcomes As reported in Blattman et al. (2014), the program had large economic impacts. Most of the women invested in petty trading and retailing, adding this to their existing farm activities. About a third rest largely saved in cash or durable assets. As a result of these investments, creased non-agricultural employment hours by 94 percent (from 5.2 to 10.1) poor intimate relationships constrain business success, we should observe neg388 among women who initially reported that their partners did not treat them 

led to small increases in reports of marital control (0.14 standard deviations, $\left.{ }_{412} p<0.05\right)$. The significant increase in the index of marital control is driven

Table 4 reports estimates of treatment heterogeneity in economic outcomes in the full program according to pre-treatment reports of poor partner relations and IPV. Results are mixed. There is little evidence of treatment heterogeneity in terms of IPV, but we do see heterogeneity related to partner relations. The most notable finding is that clients who reported that their partners do not treat them well earned $\$ 18.12$ USD less in the month, essentially wiping out the treatment effect. However, they also reported increases in durable assets and non-durable consumption, indicators of income expected to be lower among clients with worse partner relations. As anticipated, fewer clients with poor partner relations were still operating businesses, though the effect was non-significant. But counter to our expectations, the average client reported 5.8 more hours of chores per week.

[Table 4 about here.]

Partner relations, IPV and attitudes about gender norms In addition to the large economic gains overall, the program also led to small increases in the average woman's endorsement of more positive gender norms (non-significant) and in her own experience of autonomy and influence over household purchases $(p<0.10)$. At the same time, however, the program also 
in large part by the finding that women assigned to the treatment reported

422 the control group was 19.7 percent).

\section{Phase $2(\mathrm{~W}+)$ Treatment Effects}

${ }_{424}$ Table 5 and Panel B of Figure 2 show the impact of the $\mathrm{W}+$ program on our primary outcomes in Phase 2. The comparison group for Phase 2 analyses

Despite this pattern of partners attempting to capture women's earnings, however, the average woman assigned to the treatment reported a significant increase in the quality of the relationship with her partner of 0.18 standard deviations. The program effect on a self-reported index of physical, emotional, and sexual abuse among women is essentially zero (0.02, non-significant; the prevalence of any abuse within the past 8 months among women assigned to is the cohort of clients randomly assigned to participate in the standard program alone, so these effects are relative to an active control. We discuss each family of outcomes below. Detailed results are presented in Tables C.5-C.8 the Online Appendix [INSERT LINK TO ONLINE FILE]. In these tables, ITT results among women are presented first, followed by ITT results among women who had intimate male partners before Phase 2 started. We focus on these subgroups because they are the most relevant for an examination of the effect of the program on violence against women. 
Economic outcomes There was little impact of $\mathrm{W}+$ on economic outcomes. 446

Involving household partners led to a 9 percentage point (pp) decrease in the proportion of women currently engaged in business and a $6 \mathrm{pp}$ increase in the proportion of women belonging to a savings group. A greater proportion of these women thought they could obtain a relatively large loan and business advice. The ITT effects among women with intimate partners are consistent with the ITT results among all women. Notably, the average woman who partici${ }_{442}$ pated in $\mathrm{W}+$ with a partner reported a decrease in non-durable consumption of 0.31 standard deviations.

444 Grant use and expenditures On average, women assigned to W+ did not spend their grant money differently than women assigned to the standard FILE]).

4artner relations We see our largest, most significant results on outcomes describing the relationship between women and their partners. These results are generally robust to different specifications, as shown in Table C.9 in the Online Appendix [INSERT LINK TO ONLINE FILE]. On average, women assigned to $\mathrm{W}+$ reported an overall increase in the quality of their relationship with partners of 0.23 standard deviations. This index captures a woman's ratings of relationship, the couple's communication, and the partner's listening skills - all targets of the brief $\mathrm{W}+$ training. Women with intimate partners reported spending hours per day more with their partner. 
The average woman assigned to $\mathrm{W}+$ also reported receiving more supher opinion when she disagrees with her partner (0.17 points on a scale of $0-3)$. port from their partner, even for traditionally female chores. This increase in household support extended to partners helping with the business. Effects are larger - sometimes more than twice as large - among the subset of women who reported having an intimate partner prior to the start of Phase 2.

IPV and attitudes about gender norms In contrast to the results of the full program showing a small increase in marital control and essentially no effect on abuse, the $\mathrm{W}+$ results provide weak evidence of a small decrease in both outcomes. The ITT results among women with intimate partners show non-significant declines in IPV and marital control of 0.08 and 0.07 standard deviations, respectively. The only statistically significant ITT result is that the average woman with an intimate partner reported a decrease of 0.11 standard deviations in how often her partner tried to limit her contact with family and friends. Comparable effects are found in treatment-on-the-treated analyses of women with intimate partners (displayed in Table C.10 in the Online Appendix [INSERT LINK TO ONLINE FILE]). The per protocol analysis also produces similar results, although the decrease in marital control of 0.17 standard deviations is slightly larger and significant $(\mathrm{p}<0.10)$.

Women's gender attitudes were essentially unchanged, except that the average woman reported less endorsement of the idea that a wife can express Women assigned to W+ reported less autonomy and influence over household purchases (decrease of 0.07 standard deviations). 
Enterprise, Empowerment and IPV

${ }_{480}$ Discussion

This study demonstrates that, in the context of an ultrapoor asset transfer

482

484 still poor in absolute terms. We cannot rule out the possibility that a larger 502

First, we show that increasing women's earnings has no effect on intimate partner violence more than a year later. Economic success at microenterprise development may, however, subject them to increased efforts from intimate partners to capture and control earnings. Theoretically, this has three alternative interpretations. The lack of an effect on IPV could be interpreted to mean that theories about male backlash (predicting an increase in violence) and women's bargaining power (predicting a decrease in violence) have only ${ }_{494}$ a weak connection to IPV (see Aizer, 2010; Hidrobo \& Fernald, 2013). Alternatively, it could be that both theories are valid and both are operating in this context, but the effects cancel one another out. It is also possible that much larger changes in income are required to see a change in IPV in either direction.

Note, however, that the clients doubled their income - an extraordinary achievement for a program with cost-effectiveness at its core-but they are change in income would also have no effect on IPV, but it is difficult to imagine 
programs more than doubling income in a cost-effective manner. Whatever

504

506

Second, we show that a woman's relationship with her partner is important determinant of economic success. Clients who initially report poor relations do worse economically than those with better relationships, and essentially fare no better in terms of monthly earnings than women randomized to a control group waiting their turn to participate in the program. This suggests that economic assistance programs should support clients who report poor partner relations, possibly through a low-cost modification like $\mathrm{W}+$.

Engaging male partners appears to be a promising approach. We show that a slight, costless reframing of the program to a more inclusive household approach involving partners (typically husbands) and an extra day of training on gender relations, communication, and joint problem-solving leads to large positive effects on women's relationships with their partner. It does not, however, significantly improve economic outcomes or reduce IPV relative to the standard individual-based program. One interpretation is that this effort to engage men and teach relationship skills created a sense of shared goals and enabled couples to reduce frictions and misunderstandings over activities and decisions typically controlled by men in this setting. 
In terms of IPV-reduction, our results can be most closely compared to studies from South Africa and Cote D'Ivoire that show positive effects of

528 pairing economic assistance and efforts to reduce IPV might be effective with 548 a large enough dose; however, given the small number of rigorous evaluations

There are some key differences to consider, however. For instance, the intervention we studied was a small dose by design compared to the others, and IPV reduction was not the primary intervention target. The South Africa and Cote D'Ivoire trials involved regular meetings over roughly 15 months and 5 months, respectively, compared to only one day focused on gender, communication skills, and joint problem solving in the current study. Additionally, it is unclear how much time post-intervention is sufficient to detect impacts. 544 Pronyk et al. (2006) waited 24 months, but Gupta et al. (2013) — like usmeasured outcomes at 12 months post-intervention.

Taken together, the South Africa and Cote D'Ivoire studies suggest that 
and findings that are not robust to different specifications (i.e., ITT), further practice communicating with their partners in front of the group, we aimed 1973). We found modest evidence that this process began for the $\mathrm{W}+$ couples. 568 will be reinforced for supporting their wives as their behaviors are reinforced 570 the household. This process is hypothesized to create a situation of cognitive 
572

574

576

dissonance (Festinger, 1957) in which the male partner holds conflicting beliefs (e.g., women should not be allowed to travel freely outside of the village vs. giving women freedom of movement helps them to be more productive business partners) and then seeks to resolve the dissonance by updating his beliefs.

56 That said, mutual obligation and a sense of men's co-ownership can play out in complex ways, both decreasing women's autonomy and improving cooperative behavior. An alternative view of the results is that men have learned that a new and different way to influence their female partners is by spending time with them, talking to them, and persuading them to do what they (the men) want. W+ has taught them how to communicate and negotiate, so they step in and are heard more often, and also keep more control over things like business decision-making.

\section{Limitations}

This study has two main limitations. First, we relied on self-report IPV data. To the extent that clients were uncomfortable acknowledging abuse to our enumerators, this would lead to an underreporting of IPV. It seems unlikely that any underreporting would be correlated with assignment to treatment in either study, but we cannot rule this out. If women assigned to immediate treatment in Study 1 or $\mathrm{W}+$ in Study 2 were less likely to report actual abuse, it would attenuate average treatment effects. Second, we could not experimentally vary the intervention "dose" given the cluster-randomized design and power limitations. Nevertheless, this study of a slight reframing represents an important 
594

596

${ }_{604}$ Conclusions

first step. study is no exception.

Finally, our results may not generalize to all models of economic assistance (e.g., microfinance), but the intervention studied is similar to programs offered to millions of poor women around the world, thus making this an important contribution. It is possible, however, that the average woman in our sample - the poorest among a population of poor people affected by conflictwould respond differently to the program than the typical woman targeted for economic assistance. Yet these results should still have broad applicability as cash transfers continue to become more common as a humanitarian intervention in post-conflict settings.

Conditional cash transfers, unconditional cash transfers, business skills training, and vocational training are increasingly common program and policy options for improving the lives of the ultra poor-particularly poor women who are thought to be more likely than men to invest earnings in family wellbeing. A parallel goal of most economic assistance programs targeting poor women is empowerment, usually measured in terms of autonomy and bargaining power. Almost universally, studies show that these programs are effective at increas612 ing income, consumption, and wealth, but empowerment is more elusive. Our

Some theory and evidence suggests that increasing women's incomes in- 
creases their risk for IPV, others suggest this as a path to autonomy and

${ }_{622}$ References

Aizer, A. (2010). The Gender Wage Gap and Domestic Violence. The Amer-

Angelucci, M. (2008). Love on the rocks: Domestic violence and alcohol abuse 626

Angrist, J. D., \& Pischke, J.-S. (2008). Mostly Harmless Econometrics: An 628

Annan, J., Blattman, C., \& Horton, R. (2006). The state of youth and youth 630 protection in Northern Uganda: Findings from the survey of war affected youth. UNICEF,

${ }_{632}$ Bandura, A. (1973). Aggression: A social learning analysis.. Prentice-Hall. 
${ }_{634}$ Questioning gender norms with men to improve health outcomes: Evidence of impact. Global Public Health, 5, 539-553.

Blattman, C., Green, E., Jamison, J., Lehmann, M. C., \& Annan, J. (2014). 642

Devries, K., Watts, C., Yoshihama, M., Kiss, L., Schraiber, L. B., Deyessa, ${ }_{648}$ N., Heise, L., Durand, J., Mbwambo, J., Jansen, H., Berhane, Y., Ellsberg, M., \& Garcia-Moreno, C. (2011). Violence against women is strongly asso650 652

Dixon, L., \& Graham-Kevan, N. (2011). Understanding the nature and eti654

Beydoun, H. A., Beydoun, M. A., Kaufman, J. S., Lo, B., \& Zonderman, A. B. (2012). Intimate partner violence against adult women and its association with major depressive disorder, depressive symptoms and postpartum depression: A systematic review and meta-analysis. Social Science $\mathscr{G}$ Medicine, $75,959-975$. field experiment. URL: http://ssrn . com/abstract=2439488.

Bobonis, G. J., González-Brenes, M., \& Castro, R. (2013). Public transfers and domestic violence: The roles of private information and spousal control. American Economic Journal: Economic Policy, 5, 179-205. ciated with suicide attempts: Evidence from the who multi-country study on women's health and domestic violence against women. Social Science $\mathscr{G}$ Medicine, 73, 79-86.

ology of intimate partner violence and implications for practice and policy. Clinical Psychology Review, 31, 1145-1155. 
Duflo, E. (2011). Women's empowerment and economic development. Technical Report National Bureau of Economic Research.

Ellsberg, M., Arango, D. J., Morton, M., Gennari, F., Kiplesund, S., Contreras, M., \& Watts, C. (2014). Prevention of violence against women and girls: what does the evidence say? The Lancet, . doi:10.1016/ S0140-6736(14)61703-7.

Fearon, J., \& Hoeffler, A. (2014). Peaceful, stable, and resilient societies. Technical Report Paper prepared for the Copenhagen Consensus.

64 Festinger, L. (1957). A Theory of Cognitive Dissonance. Stanford, CA: Stanford University Press.

Garcia-Moreno, C., Jansen, H. A., Ellsberg, M., Heise, L., \& Watts, C. H. (2006). Prevalence of intimate partner violence: findings from the WHO multi-country study on women's health and domestic violence. The Lancet, $368,1260-1269$.

- Garcia-Moreno, C., \& Watts, C. (2011). Violence against women: an urgent public health priority. Bulletin of the World Health Organization, 89, 2-2.

672 Gupta, J., Falb, K. L., Lehmann, H., Kpebo, D., Xuan, Z., Hossain, M., Zimmerman, C., Watts, C., \& Annan, J. (2013). Gender norms and economic empowerment intervention to reduce intimate partner violence against women in rural Côte d'Ivoire: a randomized controlled pilot study. BMC International Health and Human Rights, 13, 46. 
Haushofer, J., \& Shapiro, J. (2013). Household response to income changes:

678 Evidence from an unconditional cash transfer program in kenya. Massachusetts Institute of Technology, .

${ }_{680}$ Hidrobo, M., \& Fernald, L. (2013). Cash transfers and domestic violence. Journal of Health Economics, 32, 304-319.

${ }_{682}$ Hindin, M. J., Kishor, S., Ansara, D. L., Nilsson, J. E., Brown, C., Russell, E. B., Khamphakdy-Brown, S., Btoush, R., Haj-Yahia, M. M., \& Ser${ }_{684}$ banescu, F. (2008). Intimate partner violence among couples in 10 DHS countries: predictors and health outcomes. Journal of Interpersonal Vio686 lence, 23, 1654-1663.

Hossain, M., Zimmerman, C., Kiss, L., Abramsky, T., Kone, D., Bakayoko${ }_{688}$ Topolska, M., Annan, J., Lehmann, H., \& Watts, C. (2014). Working with men to prevent intimate partner violence in a conflict-affected setting: a ${ }_{690}$ pilot cluster randomized controlled trial in rural Cote d'Ivoire. BMC Public Health, 14, 339 .

${ }_{692}$ Jewkes, R. (2002). Intimate partner violence: causes and prevention. The Lancet, 359, 1423-1429.

694 Jewkes, R., Flood, M., \& Lang, J. (2014). From work with men and boys to changes of social norms and reduction of inequities in gender relations: 696 a conceptual shift in prevention of violence against women and girls. The Lancet, . doi:10.1016/S0140-6736(14)61683-4.

${ }_{698}$ Jewkes, R., Nduna, M., Levin, J., Jama, N., Dunkle, K., Puren, A., \& 
Duvvury, N. (2008). Impact of Stepping Stones on incidence of HIV and

700

702

704

Pronyk, P. M., Hargreaves, J. R., Kim, J. C., Morison, L. A., Phetla, G., ${ }_{710}$ Watts, C., Busza, J., \& Porter, J. D. H. (2006). Effect of a structural intervention for the prevention of intimate-partner violence and HIV in rural

Saile, R., Neuner, F., Ertl, V., \& Catani, C. (2013). Prevalence and predictors 714 HSV-2 and sexual behaviour in rural South Africa: cluster randomised controlled trial. BMJ : British Medical Journal, $33 \%$.

Jewkes, R. K., Dunkle, K., Nduna, M., \& Shai, N. (2010). Intimate partner violence, relationship power inequity, and incidence of HIV infection in young women in South Africa: a cohort study. The Lancet, 376, 41-48.

Kim, J., Ferrari, G., Abramsky, T., Watts, C., Hargreaves, J., Morison, L., Phetla, G., Porter, J., \& Pronyk, P. (2009). Assessing the incremental effects of combining economic and health interventions: the image study in south africa. Bulletin of the World Health Organization, 87, 824-832.

South Africa: a cluster randomised trial. The Lancet, 368, 1973-1983.

of partner violence against women in the aftermath of war: A survey among couples in Northern Uganda. Social Science $\&$ Medicine, 86, 17-25.

Sen, A. (1999). Development as Freedom. Oxford University Press.

Skinner, B. F. (1953). Science and Human Behavior. New York: MacMillan.

${ }_{718}$ Snyder, D. K., \& Halford, W. K. (2012). Evidence-based couple therapy: current status and future directions. Journal of Family Therapy, 34, 229249. 
Stark, L., \& Ager, A. (2011). A Systematic Review of Prevalence Studies 722 of Gender-Based Violence in Complex Emergencies. Trauma, Violence, \&3 Abuse, 12, 127-134.

724 Uganda Bureau of Statistics (UBOS), \& Macro International Inc (2007). Uganda Demographic and Health Survey 2006. Technical Report UBOS 726 and Macro International Inc Calverton, Maryland.

Vyas, S., \& Watts, C. (2009). How does economic empowerment affect women's ${ }_{728}$ risk of intimate partner violence in low and middle income countries? A systematic review of published evidence. Journal of International Development, $730 \quad 21,577-602$.

World Bank (2011). World Development Report 2012: Gender Equality and ${ }_{732}$ Development. Technical Report World Bank Washington, D.C. 


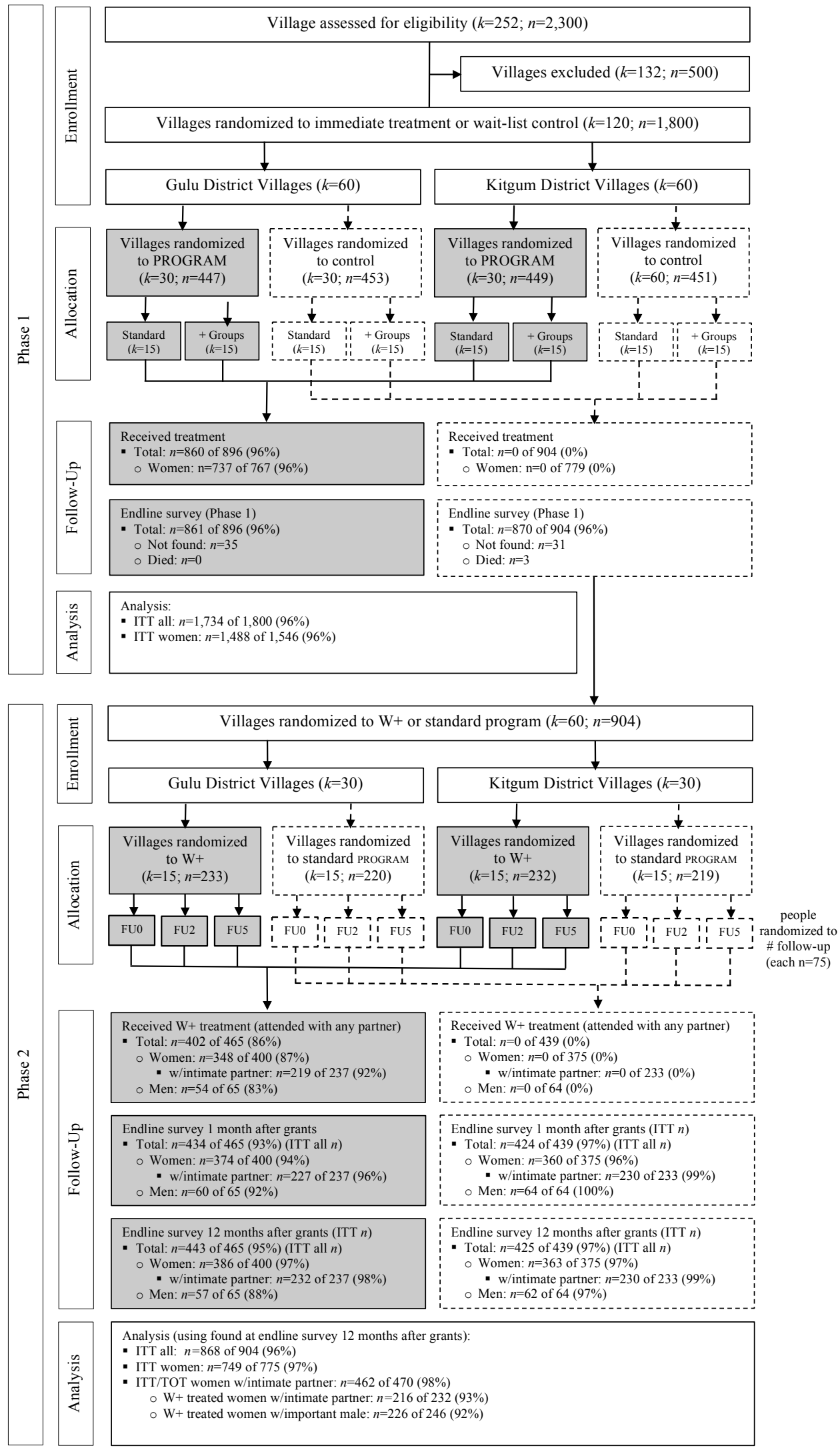

Figure 1: Participant flow diagram. 

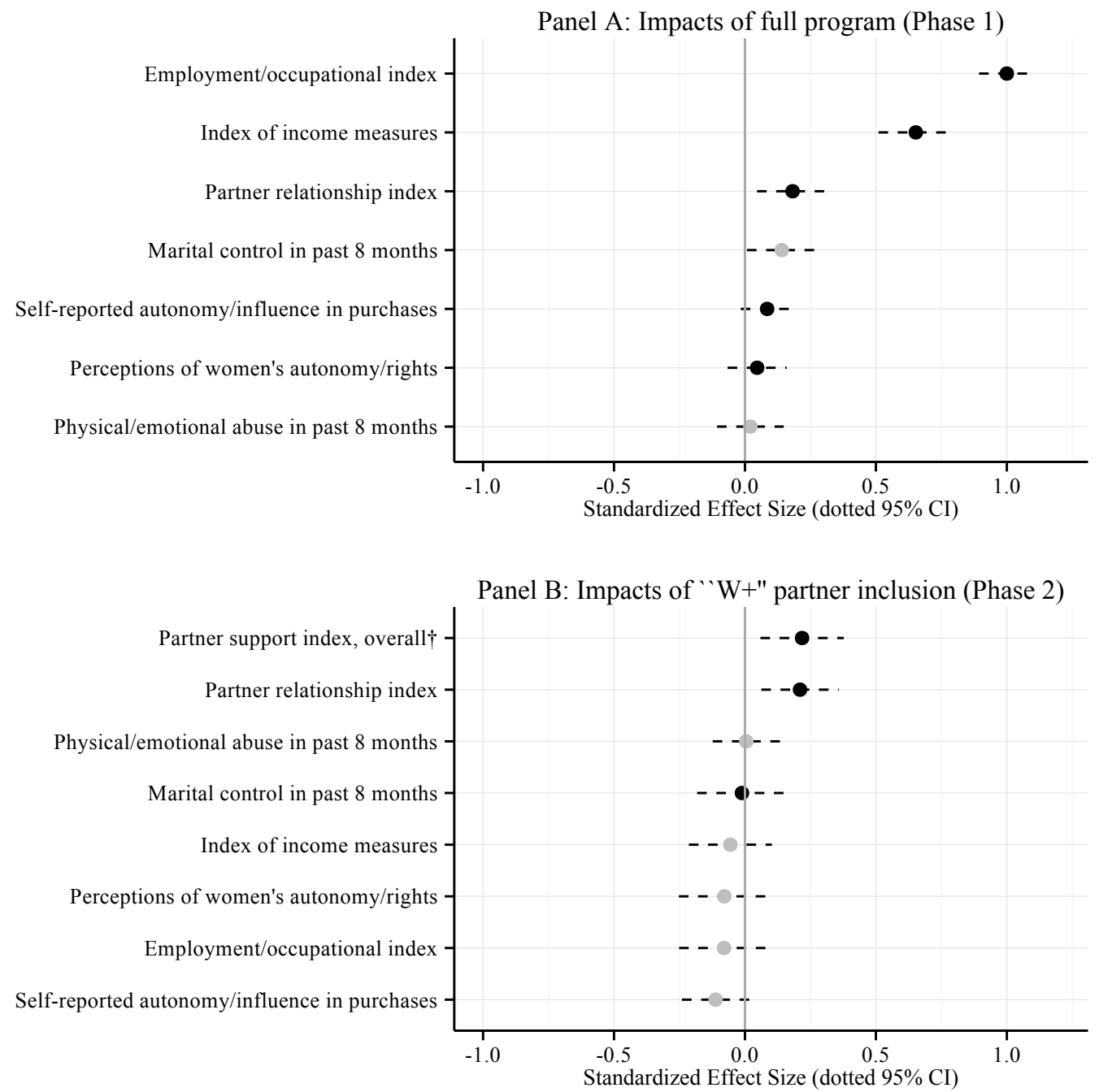

Figure 2: PANEL A Impacts of full program (Phase 1). Impacts of "W+" partner inclusion (Phase 2). These panels display the standardized results of intention-to-treat (ITT) ordinary least squares (OLS) regressions of each outcome on an indicator of assignment to treatment among women (immediate treatment in Panel A (Phase 1); W+ in panel B (Phase 2), a stratum fixed effect, and baseline covariates. The point estimates were standardized by dividing the coefficient on assignment by the control group standard deviation (Glass's $\Delta$ ). Black dots represent point estimates in the hypothesized direction (grey if not in the hypothesized direction). Dotted lines represent 95 percent confidence intervals (based on robust standard errors clustered at the village level). † Items refer to "partner who helps [client] make domestic and financial decisions" and may not refer specifically to intimate partner. 
Table 1: Construction of gender, partner relations, and IPV outcomes

\begin{tabular}{|c|c|c|}
\hline Outcome/Variable & $\begin{array}{c}\text { Scale }(>) \\
\quad(1)\end{array}$ & $\begin{array}{c}2006 \text { Uganda DHS } \\
(2)\end{array}$ \\
\hline Hours awake spent with partner in a typical day & hours $(+)$ & \\
\hline Partner relationship index & $\mathrm{z}(+)$ & \\
\hline Relationship with partner & $1-10(+)$ & \\
\hline Freq of communication with partner about family $\dagger$ & $0-3(+)$ & \\
\hline Degree of communication with partner & $1-10(+)$ & \\
\hline Partner's listening skills & $1-10(+)$ & \\
\hline Frequency of major disputes with partner & $0-3(+)$ & \\
\hline Partner treats well & $0-3(+)$ & \\
\hline Can express opinion when disagrees with partner & $0-3(+)$ & \\
\hline Partner support index, overall & $\mathrm{z}(+)$ & \\
\hline Partner support index, family & $\mathrm{z}(+)$ & \\
\hline Partner's contribution to traditionally-female chores & $0-7(+)$ & \\
\hline Partner support index, business & $\mathrm{z}(+)$ & \\
\hline Perceptions of women's autonomy/rights & $\mathrm{z}(+)$ & \\
\hline A wife can express opinions when disagrees with partner & $0-3(+)$ & \\
\hline A wife can transact in market without permission & $0-3(+)$ & \\
\hline A wife may buy clothing with own money without permission & $0-3(+)$ & \\
\hline A wife may insist on condom use if partner has disease & $0-3(+)$ & 951 \\
\hline A wife may refuse sex partner has sex with other women & $0-3(+)$ & 954 \\
\hline A husband may not beat wife for refusing him sex & $0-3(+)$ & $828(d)$ \\
\hline A husband may not beat wife for burning meal & $0-3(+)$ & $828(\mathrm{e})$ \\
\hline A husband may not beat wife for leaving without permission & $0-3(+)$ & $828(\mathrm{a})$ \\
\hline Self-reported autonomy/influence in purchases & $\mathrm{z}(+)$ & \\
\hline Can decide how to spend small amounts of money & $0-3(+)$ & 825 \\
\hline Can spend earned money without permission & $0-3(+)$ & 820 \\
\hline Can have input on spending decisions on expensive goods & $0-3(+)$ & 824 \\
\hline Physical/emotional abuse in past 8 months & z (-) & \\
\hline Partner has recently threatened harm & $0-3(-)$ & 1104(b) \\
\hline Partner has recently humiliated in front of others & $0-3(-)$ & 1104(a) \\
\hline Partner has recently beaten & $0-3(-)$ & $1105(\mathrm{~g})$ \\
\hline Partner has recently kicked or hit & $0-3(-)$ & $1105(d)$ \\
\hline Does not refuse if partner wants to have sex & $0-3(-)$ & 956 \\
\hline Marital control in past 8 months & z (-) & \\
\hline Partner has recently accused of being unfaithful & $0-3(-)$ & $1103(\mathrm{~b})$ \\
\hline Partner has recently tried to limit contact & $0-3(-)$ & $1103(d)$ \\
\hline Partner has recently taken money against will & $0-3(-)$ & \\
\hline Cannot transact in market without partner's permission & $0-1(-)$ & \\
\hline Partner has recently refused money for household needs & $0-3(-)$ & \\
\hline Has recently had to give money to partner & $0-3(-)$ & \\
\hline Physical abuse in past 8 months & $0-1(-)$ & \\
\hline Emotional abuse in past 8 months & $0-1(-)$ & \\
\hline Physical or emotional abuse in past 8 months & $0-1(-)$ & \\
\hline
\end{tabular}

Note. This table details variable construction for gender, partner relations, and IPV outcomes. Column 1 lists the scale of each outcome. The character in parentheses indicates the valence of higher values: good (+) or bad (-). Column 2 indicates whether the item was adapted from the 2006 Uganda Demographic and Health Survey. Numbers represent question numbers from the official DHS questionnaire. 
Table 2: Baseline descriptive statistics and tests of balance

\begin{tabular}{|c|c|c|c|c|c|c|c|c|c|c|}
\hline \multirow[b]{3}{*}{ Select baseline covariates } & \multicolumn{5}{|c|}{ Phase $1(n=1,800 ; k=120)$} & \multicolumn{5}{|c|}{ Phase $2(n=904 ; k=60)$} \\
\hline & \multicolumn{2}{|c|}{ Control } & \multicolumn{2}{|c|}{ Treat } & \multirow[b]{2}{*}{$\begin{array}{c}p \\
(5)\end{array}$} & \multicolumn{2}{|c|}{ Control } & \multicolumn{2}{|c|}{ Treat } & \multirow[b]{2}{*}{$\begin{array}{c}p \\
(10\end{array}$} \\
\hline & $\begin{array}{c}\mathrm{M} \\
(1)\end{array}$ & $\begin{array}{l}\text { SD } \\
(2)\end{array}$ & $\begin{array}{c}\mathrm{M} \\
(3)\end{array}$ & $\begin{array}{l}\text { SD } \\
\text { (4) }\end{array}$ & & $\begin{array}{l}\mathrm{M} \\
(6)\end{array}$ & $\begin{array}{l}\text { SD } \\
(7)\end{array}$ & $\begin{array}{c}\mathrm{M} \\
(8)\end{array}$ & $\begin{array}{l}\text { SD } \\
(9)\end{array}$ & \\
\hline \multicolumn{11}{|l|}{ Individual-level covariates } \\
\hline Age & 27.61 & 7.28 & 27.04 & 7.19 & 0.20 & 28.30 & 7.34 & 28.09 & 7.65 & 0.73 \\
\hline Female & 0.86 & 0.35 & 0.86 & 0.35 & 0.72 & 0.85 & 0.35 & 0.86 & 0.35 & 0.80 \\
\hline Married or living with partner & 0.50 & 0.50 & 0.46 & 0.50 & 0.28 & 0.50 & 0.50 & 0.47 & 0.50 & 0.62 \\
\hline Highest grade reached at school & 2.75 & 2.81 & 2.82 & 2.83 & 0.70 & 2.96 & 2.83 & 2.60 & 2.78 & 0.12 \\
\hline Reports having HIV or AIDS & 0.06 & 0.24 & 0.06 & 0.23 & 0.69 & 0.06 & 0.24 & 0.06 & 0.25 & 0.80 \\
\hline Reports positive hours in petty business & 0.04 & 0.19 & 0.03 & 0.16 & 0.21 & 0.05 & 0.21 & 0.03 & 0.16 & 0.14 \\
\hline Weekly employment, hours & 16.16 & 20.12 & 14.56 & 21.04 & 0.12 & 16.51 & 22.48 & 14.38 & 17.92 & 0.09 \\
\hline Weekly employment, hours: Farming for self & 9.01 & 14.58 & 7.69 & 15.51 & 0.08 & 9.10 & 15.35 & 8.13 & 13.47 & 0.29 \\
\hline Weekly employment, hours: Farming for wage & 4.33 & 9.99 & 3.57 & 7.48 & 0.08 & 4.41 & 11.71 & 3.99 & 7.85 & 0.51 \\
\hline Weekly employment, hours: Leje & 1.62 & 3.66 & 1.65 & 4.18 & 0.91 & 1.55 & 3.76 & 1.43 & 3.28 & 0.65 \\
\hline Weekly employment, hours: Brew & 0.48 & 1.62 & 0.54 & 1.48 & 0.45 & 0.55 & 1.90 & 0.38 & 1.26 & 0.21 \\
\hline Weekly employment, hours: Buy & 0.35 & 3.17 & 0.43 & 4.60 & 0.67 & 0.41 & 3.57 & 0.27 & 2.72 & 0.55 \\
\hline Weekly employment, hours: Other & 0.38 & 2.27 & 0.68 & 5.07 & 0.11 & 0.46 & 2.78 & 0.25 & 1.46 & 0.22 \\
\hline Weekly household chores, hours & 33.98 & 21.02 & 34.93 & 24.75 & 0.53 & 31.86 & 20.41 & 31.81 & 23.63 & 0.98 \\
\hline No employment hours in past month & 0.18 & 0.38 & 0.23 & 0.42 & 0.07 & 0.16 & 0.36 & 0.18 & 0.38 & 0.54 \\
\hline Durable assets (z-score) & -0.61 & 0.47 & -0.67 & 0.45 & 0.10 & -0.59 & 0.47 & -0.64 & 0.44 & 0.38 \\
\hline Monthly cash earnings (000s UGX) & 9.33 & 13.29 & 8.54 & 13.07 & 0.26 & 10.06 & 14.81 & 7.74 & 11.24 & 0.02 \\
\hline Member of a savings group & 0.11 & 0.31 & 0.08 & 0.27 & 0.07 & 0.12 & 0.33 & 0.10 & 0.30 & 0.43 \\
\hline Savings stock (000s UGX) & 5.47 & 16.08 & 4.24 & 14.43 & 0.20 & 6.51 & 17.60 & 4.03 & 13.55 & 0.09 \\
\hline Total outstanding loans (000s UGX) & 4.08 & 12.93 & 4.21 & 12.98 & 0.85 & 3.81 & 12.44 & 3.87 & 12.87 & 0.94 \\
\hline Can obtain 15,000 UGX loan & 0.24 & 0.43 & 0.23 & 0.42 & 0.56 & 0.24 & 0.43 & 0.22 & 0.41 & 0.43 \\
\hline Can obtain 100,000 UGX (\$50) loan & 0.04 & 0.19 & 0.05 & 0.21 & 0.34 & 0.04 & 0.19 & 0.03 & 0.18 & 0.88 \\
\hline Community maltreatment in past year & 0.16 & 0.37 & 0.19 & 0.39 & 0.14 & 0.16 & 0.37 & 0.13 & 0.34 & 0.35 \\
\hline Related to a traditional chief or LC1 & 0.30 & 0.46 & 0.25 & 0.43 & 0.01 & 0.32 & 0.47 & 0.29 & 0.45 & 0.29 \\
\hline Total traumatic war events (z-score) & 0.03 & 0.99 & -0.04 & 0.99 & 0.21 & 0.05 & 1.03 & 0.05 & 0.94 & 1.00 \\
\hline Forcibly recruited into rebel group & 0.25 & 0.43 & 0.20 & 0.40 & 0.03 & 0.25 & 0.44 & 0.25 & 0.43 & 0.92 \\
\hline Carried gun within rebel group & 0.04 & 0.19 & 0.03 & 0.17 & 0.39 & 0.03 & 0.18 & 0.04 & 0.19 & 0.74 \\
\hline Forcibly married within rebel group & 0.03 & 0.17 & 0.03 & 0.16 & 0.63 & 0.03 & 0.16 & 0.03 & 0.18 & 0.63 \\
\hline \multicolumn{11}{|l|}{ Village-level covariates } \\
\hline Village population & 649.05 & 471.44 & 749.62 & 713.78 & 0.34 & 612.02 & 295.29 & 684.11 & 589.63 & 0.54 \\
\hline Distance to capital $(\mathrm{km})$ & 44.72 & 17.19 & 46.21 & 17.54 & 0.58 & 44.25 & 15.79 & 45.22 & 18.42 & 0.81 \\
\hline Accessible by bus & 0.91 & 0.29 & 0.98 & 0.13 & 0.05 & 0.90 & 0.29 & 0.91 & 0.29 & 0.94 \\
\hline Village has a market & 0.34 & 0.47 & 0.18 & 0.39 & 0.05 & 0.34 & 0.47 & 0.34 & 0.47 & 0.97 \\
\hline Number of shops in village & 1.29 & 4.43 & 1.65 & 4.29 & 0.66 & 1.17 & 4.06 & 1.41 & 4.76 & 0.84 \\
\hline Total NGOs in village & 7.42 & 4.26 & 7.12 & 3.55 & 0.68 & 7.34 & 3.23 & 7.50 & 5.04 & 0.89 \\
\hline
\end{tabular}

Note. Individual-level covariates come from self-reported surveys. Village-level covariates come from a survey of a community leader or leaders. All Ugandan shilling (UGX)-denominated variables and all hours worked variables were top-censored at the 99th percentile to contain outliers. Missing observations at baseline were imputed at the median. Columns 1-4 and 6-9 report the mean and standard deviation of all respondents prior to Phase 1 and Phase 2, respectively. Columns 5 and 10 report the p-values on balance resulting from OLS regressions of each baseline characteristic on an indicator for treatment assignment plus a strata fixed effect, with heteroskedastic-robust standard errors clustered at the village level. 


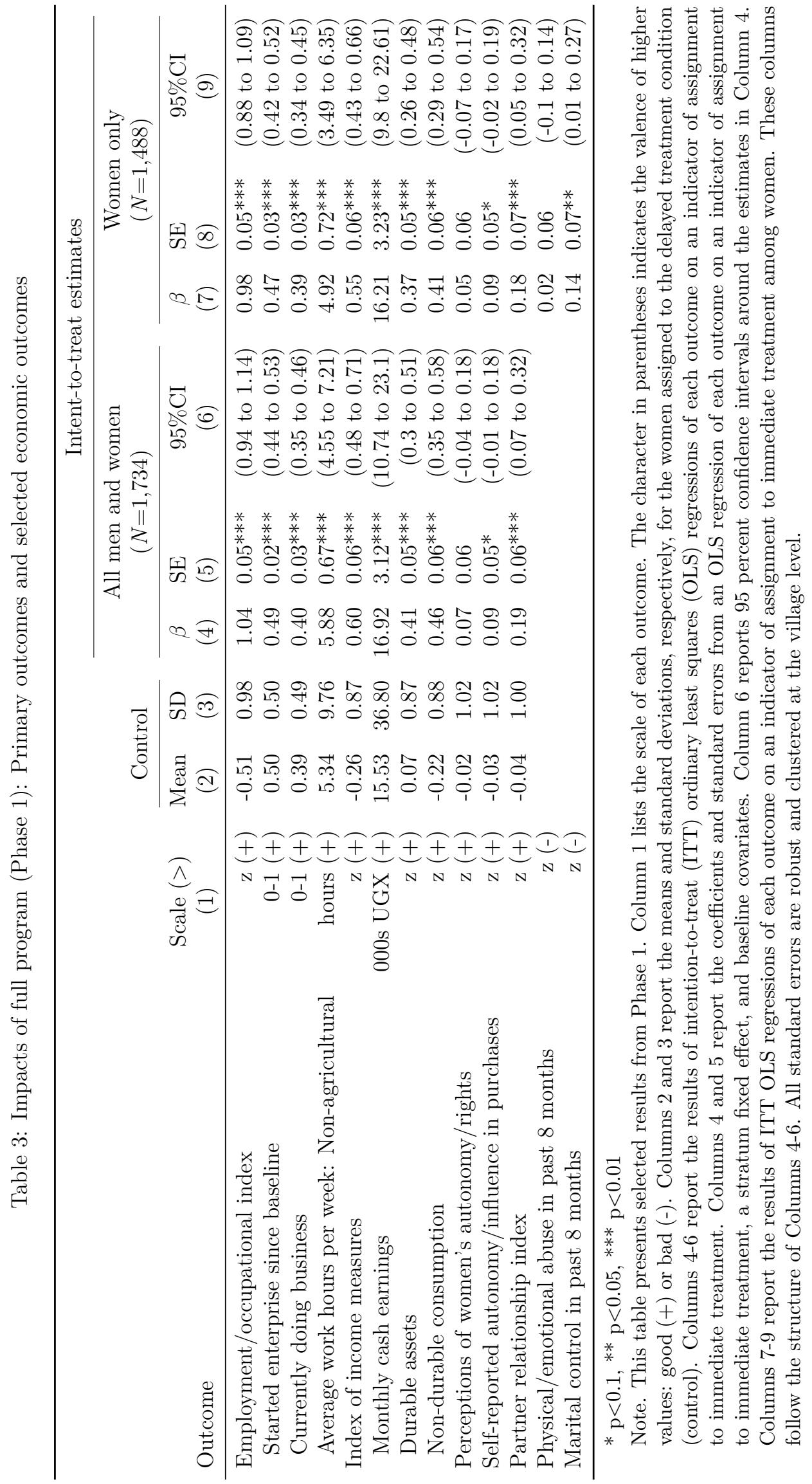




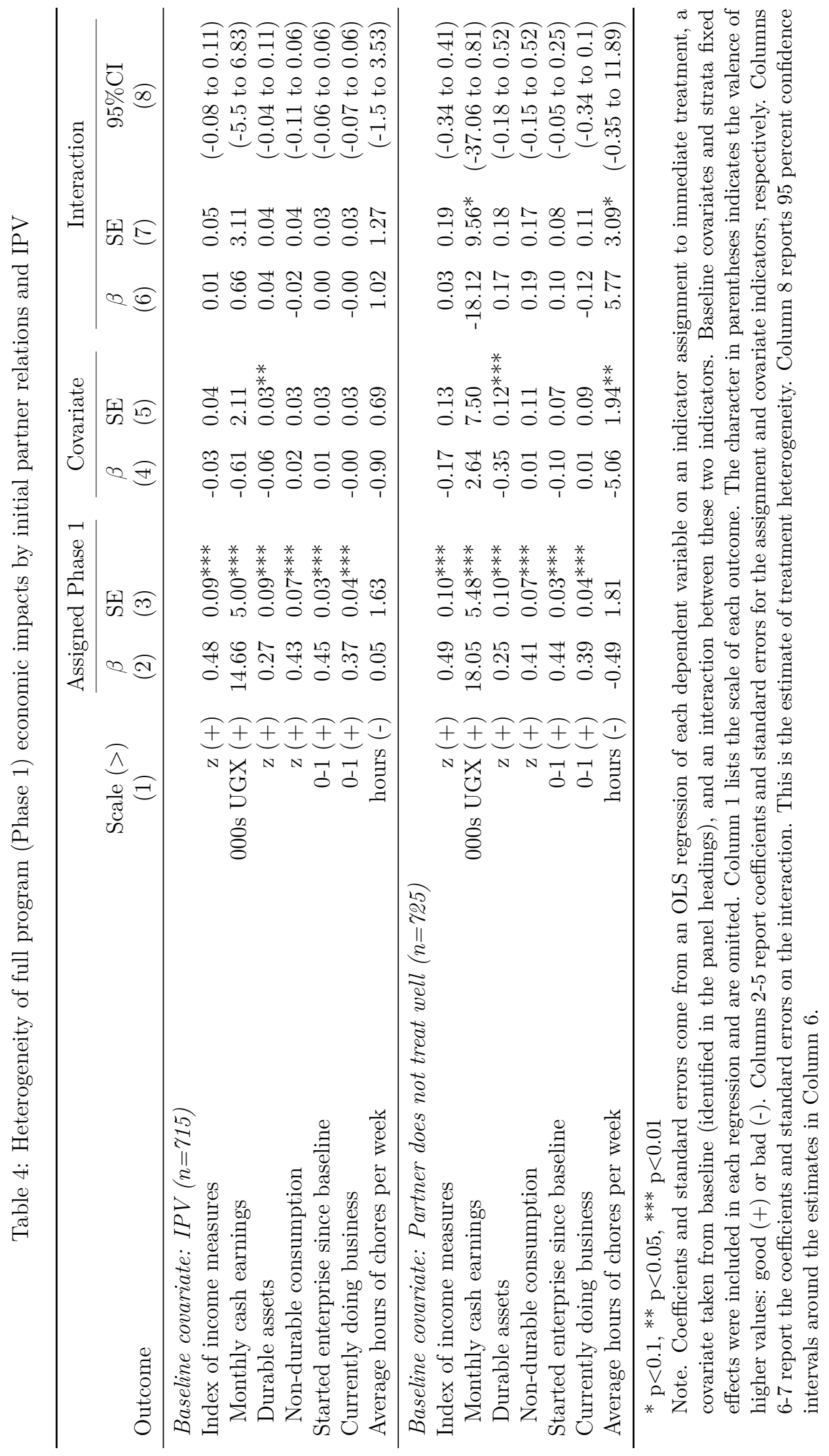




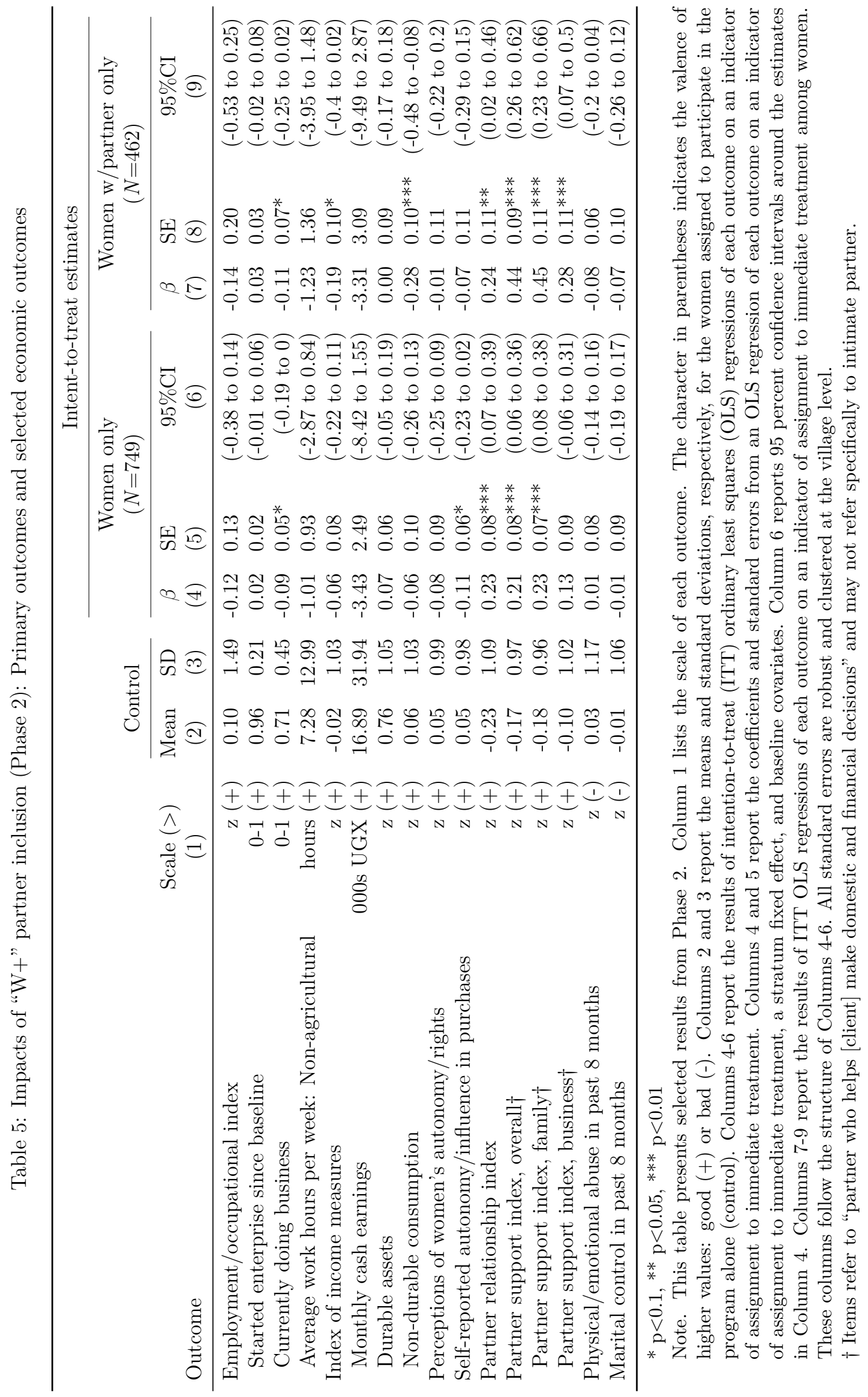




\section{Appendix A. Training programs: Aims and cur- ricula}

A copy of the training manual is available from AVSI USA on request (http: //www.avsi-usa.org/).

\section{Appendix A.1. Business skills training, standard WINGS program}

The stated objectives of the business skills training were to increase basic knowledge and skills of business management, develop confidence in enterprise initiation and management, and to help participants assess their own capabilities and motivation in entrepreneurial career and strengthen and develop business skills. The training was adapted from the CARE-Uganda Ecodev projects training manual which is based on CARE Bangladesh's Small Economic Activity Development Sector and Rural Maintenance Program.

Training and subsequent follow-up visits were led by AVSI resident field officers (RFOs), full time professional staff of the NGO. RFOs typically had tertiary education in social work, the slight majority were men, and most had at least a few years of experience on similar interventions. AVSI trained them in providing business support as well as psychological and social support. They were based in field offices at the sub-county level. Prior to administering the training, each RFO had participated in a two-week course led by an exter- 
nal facilitator. RFOs were trained using the Participatory Rural Approach Manual and the Community Resilience and Dialogue (CRD) Manual, aimed for literate and non-literate persons, respectively. Training time was divided equally between each training manual.

During this business skills training, participants were asked to address five key questions: a) Can I operate this IGA? b) Will people buy my products? c) Is the IGA profitable? d) How much money do I need to start and operate the IGA? e) Will the income from the IGA when added to other family income, be enough to pay household incomes? These key questions were practically presented to participants through lectures, small group discussion, group games, storytelling, dramatizations and role-playing by participants, large group sharing of experiences, and drawings. participants were also constantly asked to recite the five key questions that they have to ask themselves as they think about starting their businesses. After the training, participants were given two weeks to develop a business plan, at which point AVSI staff would return to review plans individually.

The curriculum outline was as follows:

- Business identification strategy and start-up process

- Business identification games

- Characteristics of an entrepreneur or good business person

- Steps to become a businessperson

- Business experience sharing

- Business management 
- Constraints on business growth and performance

- Advantages and disadvantages of being in business

- Importance of monitoring activities and progress, avoiding delays and taking timely corrective actions

- Sales and sales promotion

- Choosing location and prices

- Whether to sell on cash or credit

- What are credit sales?

- Advantages and disadvantages of credit

- Financial management

- Separation of home and business finances

- Simple record keeping

- Simple income and expenditure tracking

- Costing of products and services

- Simple budgeting

- Developing a business plan

- Definition and purpose of a business plan

- How to prepare a simple business plan

- Basic management of a group savings and credit fund

- Reasons for saving

- Structure of a group savings system

- Reasons for a credit system

- Structure of a group credit system 
Enterprise, Empowerment and IPV

\section{Appendix A.2. Business skills training, Women Plus $(\mathrm{W}+)$}

In this version of the program, facilitators taught the same business content in addition to and introducing three new topics:

- Culture, gender, and finances (societal barriers to female entrepreneurship)

- Discuss typical gender roles

- Consider how men and women can work together to achieve common goals

- Communication

- Identify good and bad communication patterns

- Learn and practice active listening skills

- Joint-problem solving

- Understand the importance of active problem solving with partners

- Learn and practice problem solving methods

Three core strategies ran throughout the training: (a) In-session modeling/practice (social cognitive theory); (b) Open discussion of barriers and cultural issues (motivational interviewing); and (c) Encouragement of reflection on personal experience and verification of concepts/lessons. 
Enterprise, Empowerment and IPV

\section{Appendix B. Measurement of Primary Outcomes}

Our primary endpoints included IPV, attitudes toward gender norms, quality of relationship with partner, support from partner, and autonomy and influence in household purchases. Items marked with the $†$ symbol refer to "partner who helps [client] make domestic and financial decisions" and may not refer specifically to the client's intimate partner.

Intimate partner violence We asked female clients a subset of questions about intimate partner violence from the 2006 Uganda DHS (Uganda Bureau of Statistics (UBOS) \& Macro International Inc, 2007). Our subset about abuse included two questions about emotional abuse (partner threatened harm; partner humiliated her in front of others), two questions about physical abuse (partner recently beat or kicked/hit client), and one question about sexual abuse (not able to refuse sex). See Table 1 in the main text for specific details. Due to space limitations in the survey, it was not possible to administer the entire domestic violence module. We analyzed 2006 Uganda DHS and found that our subset of 2 emotional abuse items and 2 physical abuse items correlated 0.87 with the full set of 12 emotional and physical violence items in the DHS (0.86 when restricted to only cases from the north).

Clients indicated whether they experienced these behaviors "often" (3), "sometimes", "rarely", or "never" (0) since a common reference point of the Easter holiday (i.e., in the past 8 months). We standardized then summed responses on these four variables to create a composite abuse score. Addition- 
ally, we created dichotomous indicators of experiencing any physical abuse, any emotional abuse, or any physical and/or emotional abuse abuse. Responses were coded 1 (any) if "often", "sometimes", or "rarely".

Our selection of this reference point - since Easter - was a conscious decision, since our priority was to maximize accuracy of our measures in the local context and the internal validity of the experimental estimates, over comparability to standard prevalence measures. In a prevalence study this would be deeply problematic. In a program evaluation, which focuses on within-sample comparisons, we felt it was the right choice.

For instance, as a result of pretesting, we did not believe that the 12 months approach minimized recall bias. Women in our sample have almost zero education, and are more attuned to seasons and holidays than the Western calendar. "In the last 12 months" is not a typical way of thinking about activity in this context. Therefore, we opted to use a common reference point of "since last Easter" to promote recall. In practice, this meant that we asked about the past 8 months rather than the past 12 months. Since we are primarily interested in the difference in IPV experiences between the treatment and control groups at endline, the choice of 8 vs 12 month recall is arbitrary. It would be problematic if we were more interested in studying the epidemiology of IPV to compare the prevalence of IPV to other studies.

Clients used the same 4-point response scale to indicate how frequently they experienced four marital control behaviors (partner accused client of being unfaithful, tried to limit her contact, taken money against her will, refused 
money for household needs) and reported whether or not they must get permission from their partner to transact in the market. We standardized all five marital control items and summed responses to create a composite marital control score.

Attitudes toward gender norms We modified several "yes/no" questions from the 2006 Uganda DHS (Uganda Bureau of Statistics (UBOS) \& Macro International Inc, 2007, p.420) regarding beliefs about whether a husband is justified in beating his wife in certain scenarios and asked clients to rate their agreement with several statements on a 4-point scale from "Strongly Disagree" to "Strongly Agree". We also asked clients to rate their agreement with five statements about a wife's autonomy to disagree with her husband, to purchase goods without permission, to refuse sex, and to insist on condom use.

Partner relationship We created a composite partner relationship score by standardizing clients' responses to seven questions. Three items asked clients to imagine a 10-step ladder and indicate on which step (1-10) they or their partner stood in terms of relationship quality, communication patterns, and listening skills. Clients also responded to four questions about relationship quality, communication, and dispute frequency on a 4-point scale from "often" (0), "sometimes", "rarely", or "never" (3).

Partner support We constructed two composite scores for partner support of household and business activities, and we combined these scores into an 
overall partner support composite. Household support was measured by asking clients to indicate "yes/no" whether their partner helped with 7 traditionally female chores (e.g., washing clothes, cooking) and 2 traditionally male chores (keeping the animals, hunting), in addition to providing an overall rating of the partner's helpfulness with chores since the program. Business support was measured by asking clients to rate their partner's support for the business"often" (3), "sometimes", "rarely", or "never" (0) - and involvement in the business (1-10 ladder).

Autonomy/Influences in purchases We constructed a composite score from three questions representing a client's autonomy and influence in purchases (can decide how to spend money, can use earnings to buy clothes without permission, has a say in purchase of large household assets). Clients responded on a 4-point scale: "often" (3), "sometimes", "rarely", or "never" $(0)$. 


\section{Appendix C. Supplemental Figures and Tables}




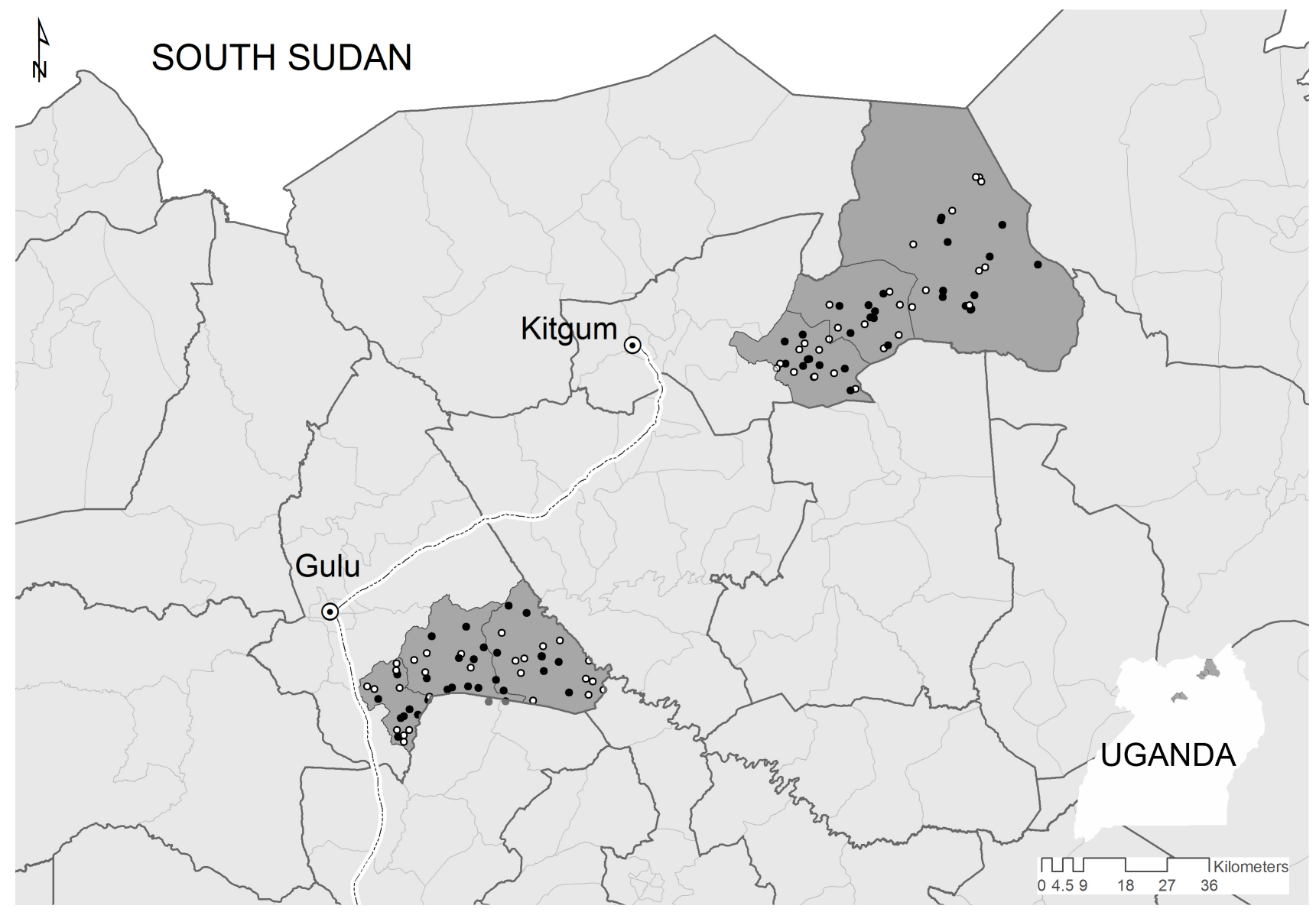

Figure C.1: Map of study villages. Thick and thin lines indicate district and sub-county boundaries. Villages assigned to Phase 1 are represented by black circles. Villages assigned to Phase 2 are hollow circles. 
Table C.1: Pre-treatment covariates

Variable

Baseline:

Age

Female

Household size

Married or living with partner

Sole earner in $\mathrm{HH}$

\# of children

Non-Acholi

Currently in school

Highest grade reached at school

Literate

Speaks english

Month of training

Digit recall score

Reports positive hours in petty business

Hours worked:

Farming for self or caring for own animals (capped at p99)

Agricultural labor for others (capped at p99)

Casual labor (capped at p99)

Brewing (capped at p99)

Petty trading/business (capped at p99)

Other skilled and unskilled labor (capped at p99)

Average hours of chores per week (capped at p99)

No employment hours in past month

Durable assets (z-score)

Monthly cash earnings (000s UGX)

Montly gross cash earnings of other $\mathrm{HH}$ earner 
Table C.1 - continued from previous page

Variable

Member of a savings group

Savings stock (000s UGX)

Total outstanding loans (000s UGX)

Can obtain 15,000 UGX loan

Can obtain 100,000 UGX (\$50) loan

Family support index, z-score

Community participation, z-score

Friends/neigbors support index (z-score)

Number of groups in

Community maltreatment in past year

Domestic violence, z-score

Decision-making index, z-score

Attitudes towards women's independence, z-score

Related to a traditional chief or LC1

Additive index of health (higher:better)

Reports having HIV or AIDS

Depression Index

Total traumatic war events (z-score)

Forcibly recruited into rebel group

Carried gun within rebel group

Forcibly married within rebel group

Bore a child in a forced marriage

Index of risk aversion (z-score)

Patience index (z-score)

Village Characteristics:

Village population

Mean Education

Experimental respondents per village

Remoteness: Index 
Table C.1 - continued from previous page

Variable

Price level: Index

Cost of renting land (sq root)

Village was a camp

Total NGOs in village

Number of vendors

Number of kiosks

Number of shops in village

Number of tailors

Number of hotels/restaurants

Commodity market visits

Distance to capital $(\mathrm{km})$

Gulu dummy

Average inverse distance to simulated treatment villages

Inverse distance measure to treated villages within district and within radius of $4 \mathrm{~km}$ Phase 1 endline:

Married or living with a partner

Reports positive hours in petty trading

Currently doing business

Started enterprise since baseline

Average employment hours per week: Agricultural

Average employment hours per week: Non-agricultural

Average hours of chores per week

No employment hours in past month

Main occupation is agricultural

Durable assets (z-score)

Monthly gross cash earnings

Non-durable consumption (z-score)

Member of a savings group

Savings (000s UGX) 
Table C.1 - continued from previous page

Variable

Debts (000s UGX)

Perceived access to credit (z-score)

Community participation (z-score)

Friends/neigbors support index (z-score)

Decision-making index, z-score

Autonomy/influence in purchases (z-score)

Social support received (z-score)

Attitudes towards women's independence, z-score

Number of groups in

Additive index of health (z-score)

Depression Index

Patience index (z-score) 
Table C.2: Comparison of clients to non-clients within the village (Control villages only, at Phase 1 endline)

\begin{tabular}{lcc}
\hline \hline & & Non-clients 17- \\
Covariate & Clients (N=917) & $40(\mathrm{~N}=1,116)$ \\
\cline { 2 - 3 } & Mean & Mean \\
\hline Female & $85 \%$ & $(3)$ \\
Age & 28 & $56 \%$ \\
Years of education & 2.8 & 30 \\
Average weekly work hours & 15.0 & 4.8 \\
Agricultural weekly hours & 9.7 & 24.7 \\
$\quad$ Working on your own farm & 3.5 & 18.1 \\
$\quad$ Agricultural labor for others & 1.8 & 11.6 \\
$\quad$ Taking care of own animals & 4.3 & 3.4 \\
Non-agricultural weekly hours & 5.5 & 3.1 \\
$\quad$ Brewing alcohol/beer & 0.9 & 6.5 \\
$\quad$ Petty trading & 1.4 & 0.7 \\
Casual non-agricultural labor & 1.9 & 0.9 \\
$\quad$ Skilled non-agricultural labor & 0.5 & 1.3 \\
Other & 0.8 & 2.5 \\
No employment in past month & $8 \%$ & 1.2 \\
Reports any hours in petty business & $16 \%$ & $5 \%$ \\
Monthly cash earnings, 000s UGX & 15.8 & $17 \%$ \\
Monthly household consumption, 000s & & 13.8 \\
UGX & 108.4 & 141.1 \\
Durable assets (z-score) & -0.18 & 0.02 \\
Thatch roof & 0.00 & 0.01 \\
Number of goats & 0.97 & 1.29 \\
Number of bicycles & 0.39 & 0.63 \\
Number of mobile phones & 0.14 & 0.39 \\
\hline \hline
\end{tabular}

Notes: Individual-level covariates come from a self-reported survey of all respondents. All Ugandan shilling (UGX)-denominated variables and all hours worked variables were top-censored at the 99th percentile to contain outliers. Column 1 reports the mean of all 917 phase 1 endline respondents who were not treated in phase 1 . Columns 2 reports the mean for 1787 non-client respondents ages 17 to 40 , and Column 3 reports the means for all 2420 adult non-client respondents. 
Table C.3: Survey response rates

\begin{tabular}{|c|c|c|c|c|c|c|c|c|}
\hline \multirow[b]{2}{*}{ Survey round } & \multirow{2}{*}{$\begin{array}{c}\text { Median } \\
\text { survey date } \\
(\mathrm{MM} / \mathrm{YY}) \\
(1)\end{array}$} & \multicolumn{2}{|c|}{ Observations } & \multicolumn{5}{|c|}{ Response rates } \\
\hline & & $\begin{array}{c}\text { Total sought } \\
(2)\end{array}$ & $\begin{array}{l}\text { Obs. } \\
\text { (3) }\end{array}$ & $\begin{array}{l}\text { All } \\
(4) \\
\end{array}$ & $\begin{array}{c}\text { Control } \\
(5)\end{array}$ & $\begin{array}{c}\text { Treatment } \\
(6)\end{array}$ & $\begin{array}{c}\text { Difference } \\
(7)\end{array}$ & $\begin{array}{c}\mathrm{p} \text {-value } \\
(8)\end{array}$ \\
\hline \multicolumn{9}{|l|}{ Phase 1} \\
\hline Baseline & $5 / 09$ & 1,800 & 1,800 & $100.0 \%$ & $100.0 \%$ & $100.0 \%$ & $0.0 \%$ & \\
\hline Endline & $12 / 10$ & 1,800 & 1,734 & $96.3 \%$ & $96.6 \%$ & $96.1 \%$ & $-0.5 \%$ & 0.62 \\
\hline \multicolumn{9}{|l|}{ Phase 2} \\
\hline Baseline & $12 / 10$ & 904 & 882 & $97.6 \%$ & $97.8 \%$ & $97.4 \%$ & $-0.4 \%$ & 0.72 \\
\hline Endline (1 mo.) & $9 / 11$ & 904 & 858 & $94.9 \%$ & $93.1 \%$ & $95.9 \%$ & $2.8 \%$ & 0.13 \\
\hline Endline (1 yr.) & $7 / 12$ & 904 & 868 & $96.0 \%$ & $95.0 \%$ & $96.6 \%$ & $1.6 \%$ & 0.29 \\
\hline
\end{tabular}

Notes: Column (1) reports the median survey date. Column (2) reports the full study sample sought in each phase. Column (3) reports the final number of observations by survey round. Columns (4)-(7) report the corresponding response rates overall, by treatment status, and the treatment-control difference (calculated via regression, controlling for baseline district). Column (8) reports p-value on the difference term, using robust standard errors clustered by village. There were 1800 study subjects in Phase 1. Baseline data in Phase 2 includes the 847 original sample members from 2009, plus 2011 data on the 57 new respondents who replaced those who died or left the village. 
Table C.4: Correlates of attrition

\begin{tabular}{lcc}
\hline \hline & \multicolumn{2}{c}{ Dependent variable: Unfound } \\
\cline { 2 - 3 } & Coeff. & Std. Err. \\
\hline Assigned to treatment at P1 & 0.0119 & {$[.012]$} \\
Assigned to group dynamics & -0.0170 & {$[.013]$} \\
Assigned to 2 follow-ups & -0.0220 & {$[.015]$} \\
Assigned to 5 follow-ups & 0.0107 & {$[.015]$} \\
Phase 2 dummy & 0.0179 & {$[.013]$} \\
Gulu district & -0.0264 & {$[.008]^{* * *}$} \\
Age & -0.0028 & {$[.001]^{* * *}$} \\
Female & -0.0187 & {$[.014]$} \\
Married or living with partner & -0.0132 & {$[.008]$} \\
Highest grade reached at school & -0.0032 & {$[.001]^{* * *}$} \\
Currently in school & 0.0532 & {$[.021]^{* * *}$} \\
Average farm work hours per week & -0.0001 & {$[0000]$} \\
Average nonfarm work hours per week & -0.0003 & {$[0000]$} \\
Durable assets, z-score & 0.0069 & {$[.009]$} \\
Monthly cash earnings, 000s UGX & -0.0002 & {$[0000]$} \\
Activities of daily life, z-score & -0.0062 & {$[.005]$} \\
Symptoms of distress, z-score & 0.0004 & {$[.004]$} \\
Village population & 0.0000 & {$[0000]$} \\
Village remoteness, z-score & -0.0025 & {$[.004]$} \\
\hline Observations & 2704 & \\
R2 & 0.0283 & \\
P(baseline covariates are jointly insignificant) & 0.0000 & \\
P(treatment assignments are jointly insignificant) & 0.4457 & \\
\hline \hline$* * *$ p $<0.01, * *$ p $<0.05 *$ p $<0.1$ & & \\
& & \\
& &
\end{tabular}

$* * * \mathrm{p}<0.01, * * \mathrm{p}<0.05, * \mathrm{p}<0.1$ 
Enterprise, Empowerment and IPV

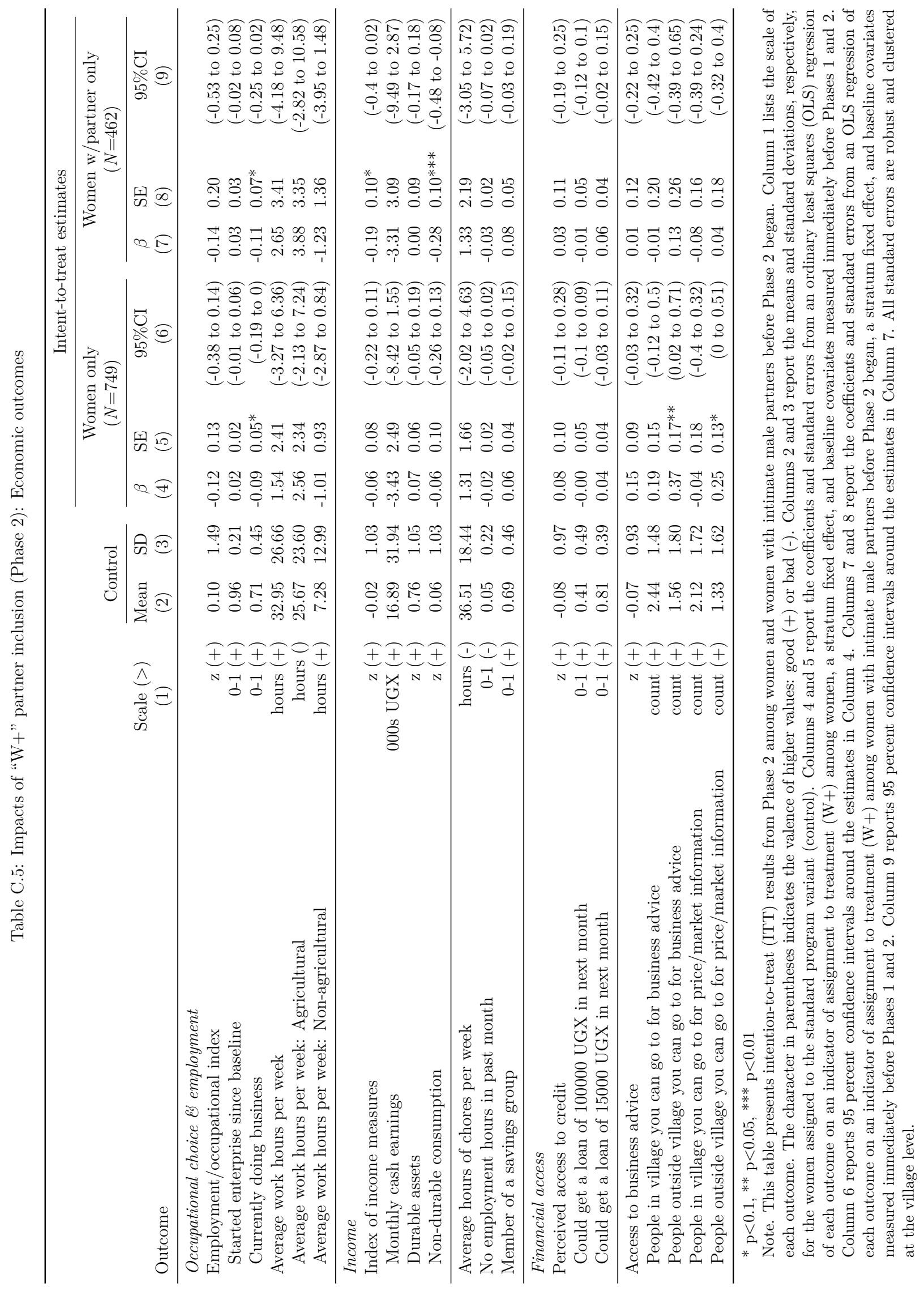




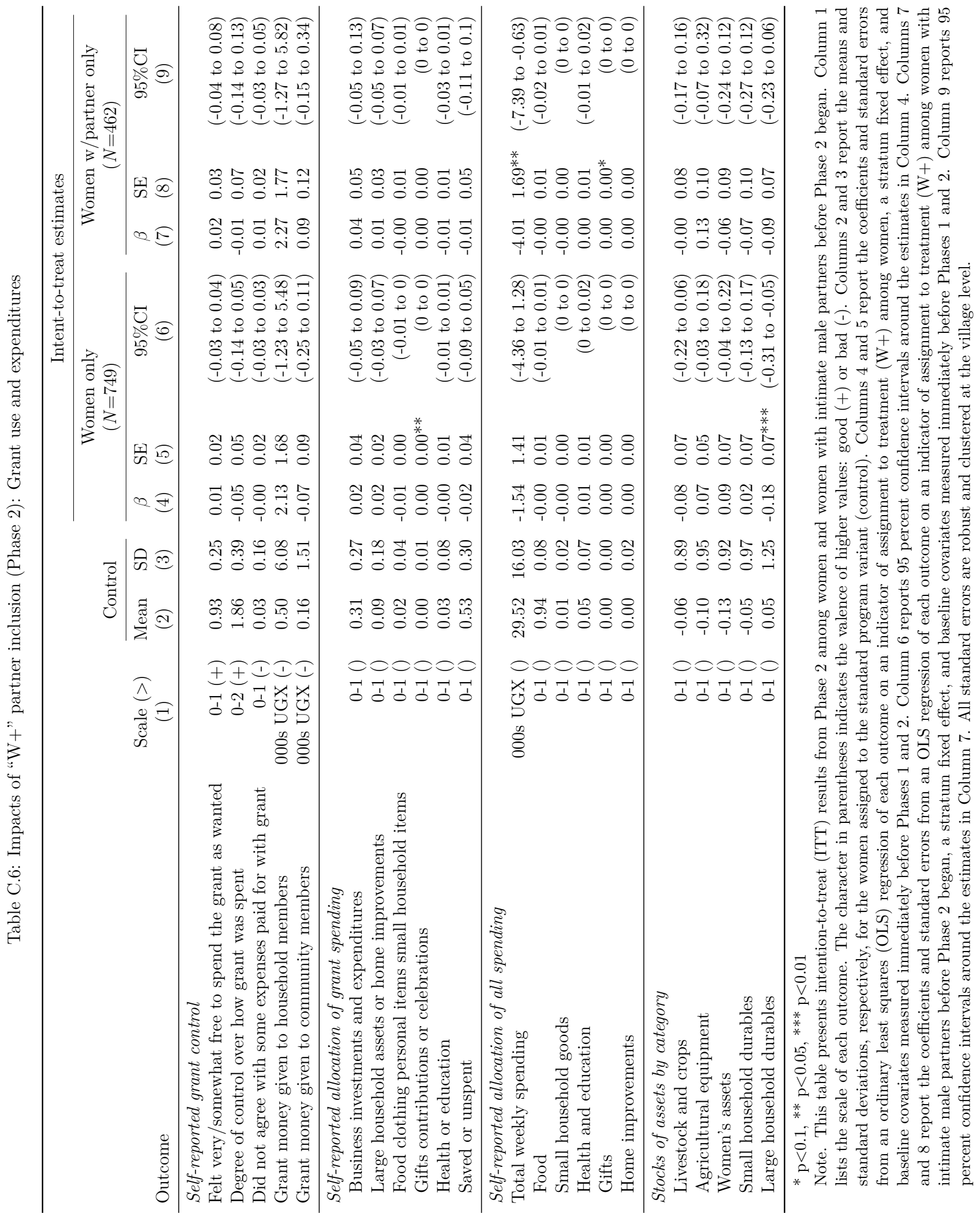




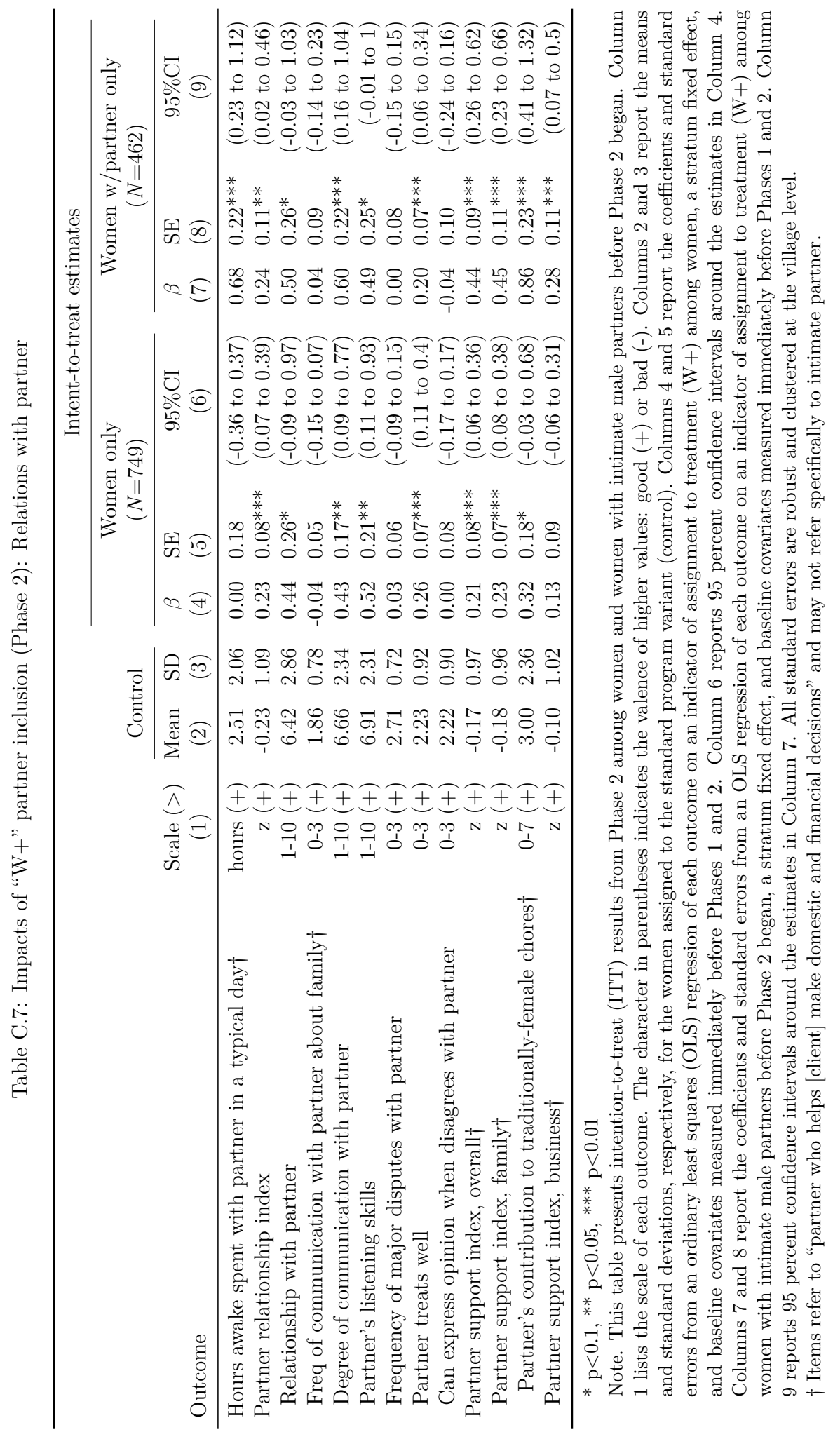




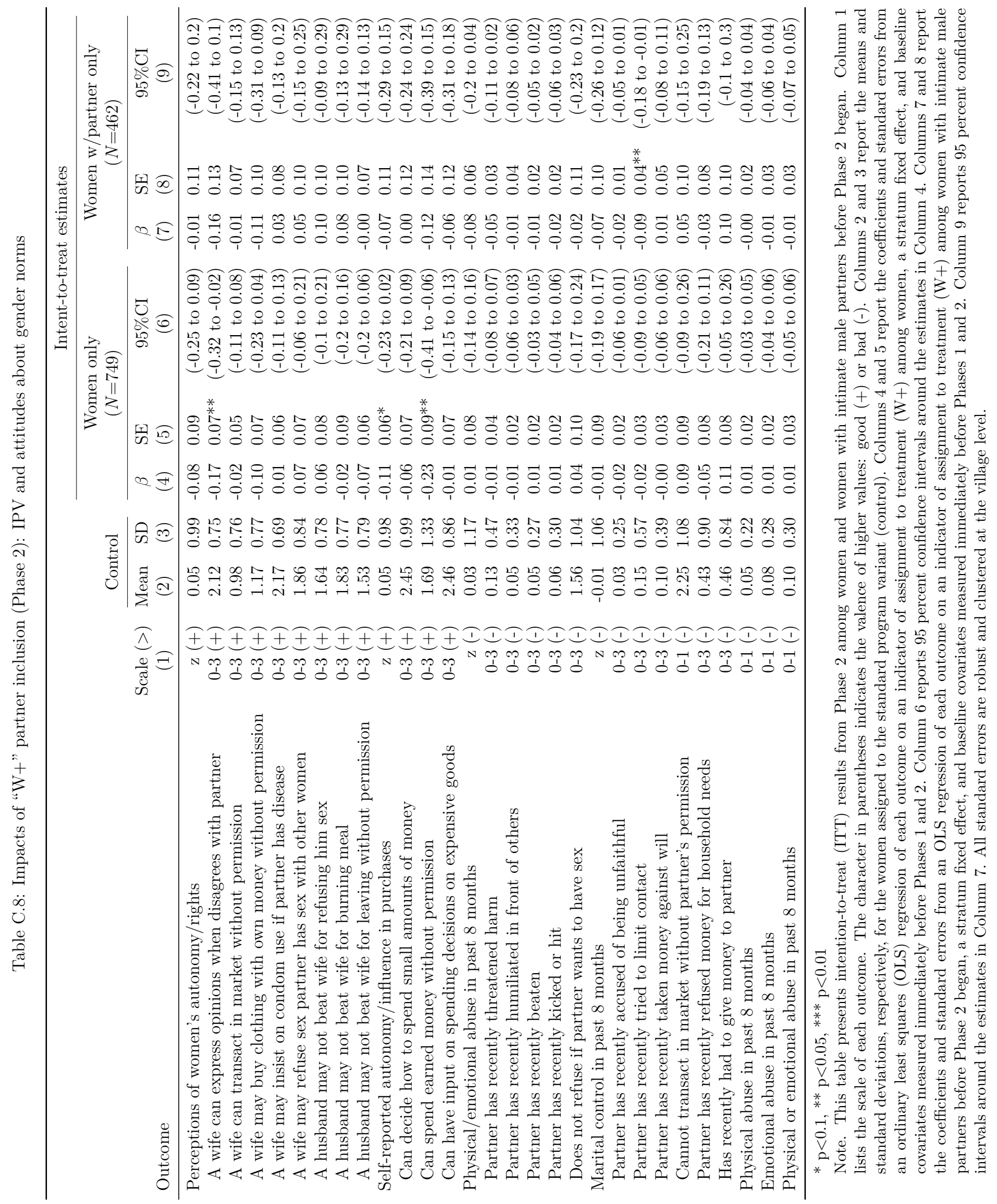


Table C.9: Sensitivity

Phase 1

Phase 2

\begin{tabular}{|c|c|c|c|c|c|c|c|}
\hline \multirow[b]{3}{*}{ Dependent variable } & \multicolumn{3}{|c|}{ Program impact under alternative models } & \multicolumn{4}{|c|}{ W+ impact under alternative models (all women) } \\
\hline & \multicolumn{2}{|c|}{ ITT estimate } & \multicolumn{2}{|l|}{ Attrition bounds } & \multicolumn{2}{|l|}{ ITT estimate } & \multirow{2}{*}{$\begin{array}{c}\text { Attrition bounds } \\
\text { Replace missing } \\
\text { with } 90 / 10 \\
\text { percentiles } \\
(7)\end{array}$} \\
\hline & $\begin{array}{c}\text { Main } \\
\text { Specification } \\
(1)\end{array}$ & $\begin{array}{c}\text { Without baseline } \\
\text { covariates } \\
(2)\end{array}$ & $\begin{array}{c}\text { Replace missing } \\
\text { with } 90 / 10 \\
\text { percentiles } \\
\text { (3) }\end{array}$ & $\begin{array}{c}\text { Main } \\
\text { specification } \\
\text { from Table } 4 \\
(4) \\
\end{array}$ & $\begin{array}{c}\text { Without } \\
\text { baseline } \\
\text { covariates } \\
(5) \\
\end{array}$ & $\begin{array}{l}\text { Difference-in- } \\
\text { differences } \\
\text { estimate } \\
(6) \\
\end{array}$ & \\
\hline \multirow[t]{2}{*}{ Started Enterprise Since Baseline } & 0.486 & 0.476 & 0.467 & 0.023 & 0.005 & 0.135 & 0.031 \\
\hline & {$[.023]^{* * *}$} & {$[.026]^{* * *}$} & {$[.023] * * *$} & {$[.017]$} & {$[.014]$} & {$[.049] * * *$} & {$[.016]^{*}$} \\
\hline \multirow[t]{2}{*}{ Currently doing business } & 0.405 & 0.405 & 0.350 & -0.094 & -0.095 & -0.039 & -0.089 \\
\hline & {$[.026]^{* * *}$} & {$[.028]^{* * *}$} & {$[.026]^{* * *}$} & {$[.048]^{*}$} & {$[.046]^{* *}$} & {$[.055]$} & {$[.052]^{*}$} \\
\hline \multirow[t]{2}{*}{ Index of income measures (z-score) } & 0.596 & 0.507 & 0.508 & -0.058 & -0.072 & -0.090 & -0.029 \\
\hline & {$[.06]^{* * *}$} & {$[.073]^{* * *}$} & {$[.059]^{* * *}$} & {$[.082]$} & {$[.105]$} & {$[.093]$} & {$[.084]$} \\
\hline \multirow[t]{2}{*}{ Monthly cash earnings, 000 s UGX } & 16.919 & 15.709 & 15.043 & -3.434 & -4.962 & -2.936 & -1.777 \\
\hline & {$[3.121]^{* * *}$} & {$[3.167]^{* * *}$} & {$[2.949]^{* * *}$} & [2.493] & {$[2.307]^{* *}$} & [3.316] & [2.289] \\
\hline \multirow[t]{2}{*}{ Durable assets, z-score } & 0.406 & 0.287 & 0.318 & 0.071 & 0.206 & 0.137 & 0.089 \\
\hline & {$[.054] * * *$} & {$[.075]^{* * *}$} & {$[.055]^{* * *}$} & {$[.06]$} & {$[.129]$} & {$[.075]^{*}$} & {$[.067]$} \\
\hline \multirow[t]{2}{*}{ Non-durable consumption, z-score } & 0.464 & 0.437 & 0.388 & -0.063 & -0.158 & -0.157 & -0.060 \\
\hline & {$[.059]^{* * *}$} & {$[.062]^{* * *}$} & {$[.057]^{* * *}$} & {$[.097]$} & {$[.1]$} & {$[.107]$} & {$[.097]$} \\
\hline \multirow[t]{2}{*}{ Perceptions of women's autonomy/rights } & 0.066 & 0.044 & -0.025 & -0.078 & -0.143 & -0.232 & -0.076 \\
\hline & {$[.056]$} & {$[.063]$} & {$[.056]$} & {$[.086]$} & {$[.108]$} & {$[.093]^{* *}$} & {$[.091]$} \\
\hline \multirow[t]{2}{*}{ Self-reported autonomy/influence in purchases } & 0.088 & 0.054 & -0.011 & -0.109 & -0.171 & -0.266 & -0.118 \\
\hline & {$[.048]^{*}$} & {$[.062]$} & {$[.046]$} & {$[.063]^{*}$} & {$[.085]^{* *}$} & {$[.09]^{* * *}$} & {$[.069]^{*}$} \\
\hline \multirow[t]{2}{*}{ Partner relationship index } & 0.195 & 0.073 & 0.052 & 0.228 & 0.269 & 0.246 & 0.239 \\
\hline & {$[.063]^{* * *}$} & {$[.07]$} & {$[.062]$} & {$[.08]^{* * *}$} & {$[.083] * * *$} & {$[.102] * *$} & {$[.092] * *$} \\
\hline \multirow[t]{2}{*}{ Physical/emotional abuse in the past 8 months } & 0.025 & 0.099 & -0.069 & 0.006 & -0.024 & 0.116 & -0.022 \\
\hline & {$[.062]$} & {$[.065]$} & {$[.058]$} & {$[.075]$} & {$[.077]$} & {$[.087]$} & {$[.072]$} \\
\hline \multirow[t]{2}{*}{ Marital control in the past 8 month } & 0.141 & 0.207 & 0.036 & -0.012 & 0.013 & -0.001 & -0.026 \\
\hline & {$[.065]^{* *}$} & {$[.069] * * *$} & {$[.063]$} & {$[.091]$} & {$[.096]$} & {$[.132]$} & {$[.091]$} \\
\hline \multicolumn{8}{|c|}{ 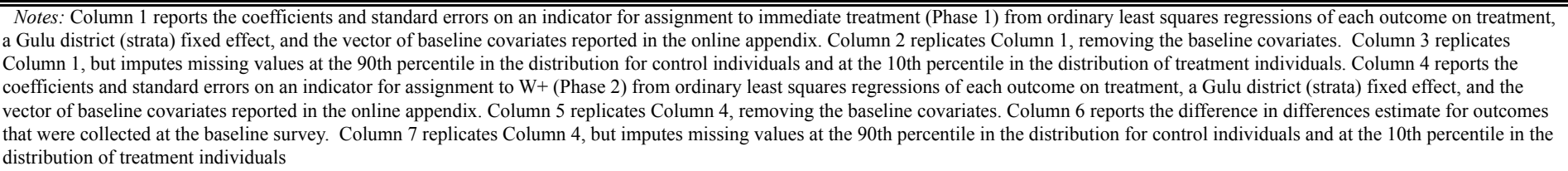 } \\
\hline
\end{tabular}




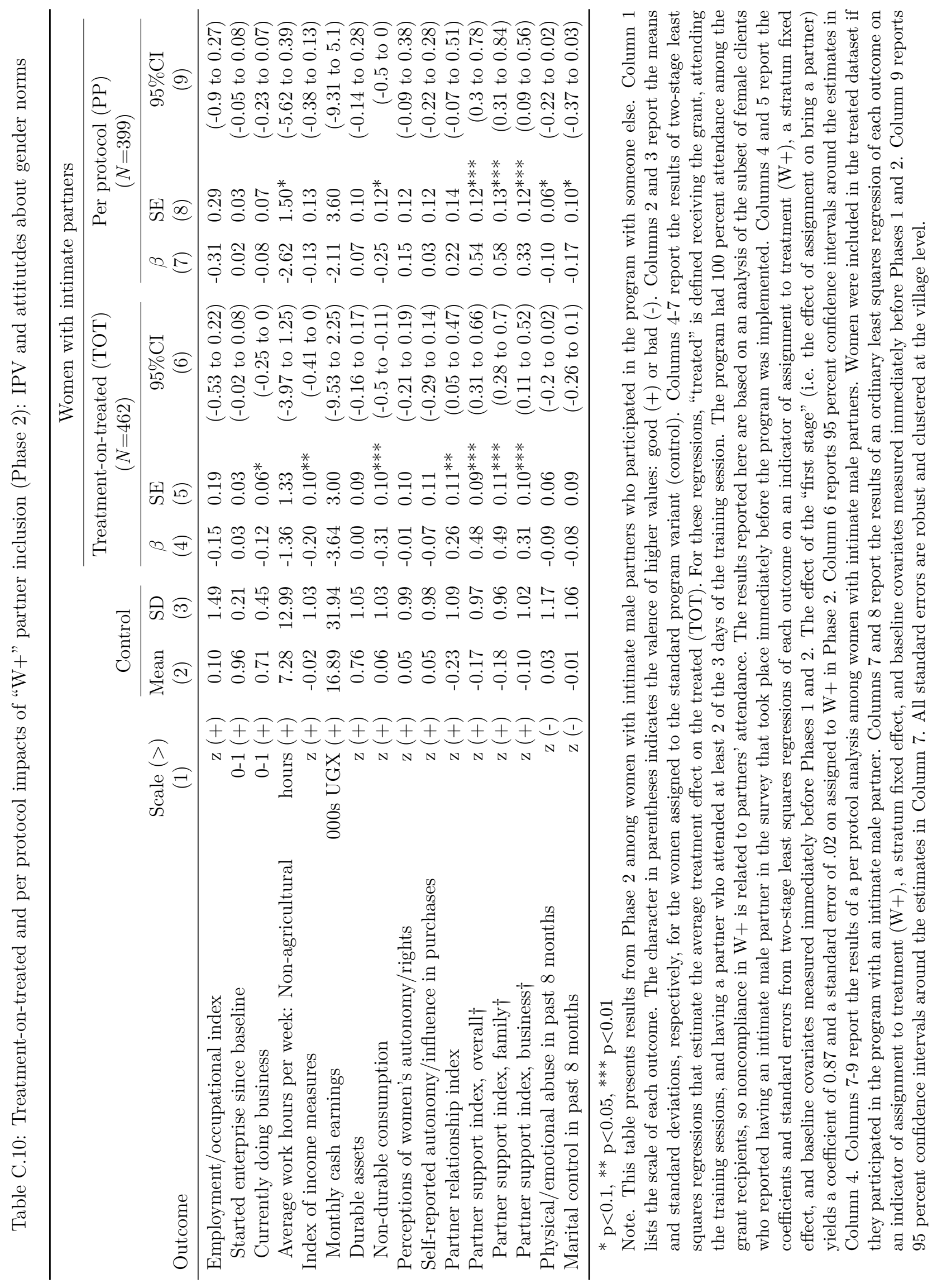

